\section{Lentiviral Hematopoietic Stem Cell Gene Therapy in Patients with Wiskott-Aldrich Syndrome}

Alessandro Aiuti, * Luca Biasco, Samantha Scaramuzza, Francesca Ferrua, Maria Pia Cicalese, Cristina Baricordi, Francesca Dionisio, Andrea Calabria, Stefania Giannelli, Maria Carmina Castiello, Marita Bosticardo, Costanza Evangelio, Andrea Assanelli, Miriam Casiraghi, Sara Di Nunzio, Luciano Callegaro, Claudia Benati, Paolo Rizzardi, Danilo Pellin, Clelia Di Serio, Manfred Schmidt, Christof Von Kalle, Jason Gardner, Nalini Mehta, Victor Neduva, David ]. Dow, Anne Galy, Roberto Miniero, Andrea Finocchi, Ayse Metin, Pinaki P. Banerjee, Jordan S. Orange, Stefania Galimberti, Maria Grazia Valsecchi, Alessandra Biffi, Eugenio Montini, Anna Villa, Fabio Ciceri, Maria Grazia Roncarolo, Luigi Naldini

Introduction: Wiskott-Aldrich syndrome (WAS) is a primary immunodeficiency characterized by eczema, thrombocytopenia, infections, and a high risk of developing autoimmunity and cancer. In a recent clinical trial, a $\gamma$-retroviral vector was used to introduce a functional WAS gene into autologous hematopoietic stem/progenitor cells (HSCs), followed by reinfusion of the gene-corrected HSCs into the patients. This strategy provided clinical benefit but resulted in expansion and malignant transformation of hematopoietic clones carrying vector insertions near oncogenes, thus increasing leukemia risk. We have developed a clinical protocol for WAS based on lentiviral vector (LV) gene transfer into HSCs.

Methods: Three patients with WAS were treated in a phase I/II clinical trial with gene-corrected HSCs after pretreatment with a reduced-intensity myeloablative regimen. Autologous CD34+ cells were transduced with an optimized LV carrying the WAS gene under the control of its endogenous promoter. Patients were monitored for up to 2.5 years after gene therapy by molecular, immunological, and clinical tests. We also investigated the genomic distribution of LV integration sites in the patients' bone marrow and peripheral blood cell lineages.

Results: Administration of autologous HSCs transduced with LV at high efficiency $(>90 \%)$ resulted in robust (25 to $50 \%$ ), stable, and long-term engraftment of gene-corrected HSCs in the patients' bone marrow. WAS protein expression was detected in myeloid cells at similar rates and in nearly all circulating platelets and lymphoid cells. In vitro T cell proliferative responses, natural killer cell cytotoxic activity, immune synapsis formation, and suppressive function of $T$ regulatory cells were normalized. In all three patients, we observed improved platelet counts, protection from bleeding and severe infections, and resolution of eczema. Vector integration analyses on $>35,000$ unique insertion sites showed distinct waves of HSC clonal output, resulting in highly polyclonal multilineage hematopoietic reconstitution. In contrast to $\gamma$-retroviral gene therapy, our LV-based therapy did not induce in vivo selection of clones carrying integrations near oncogenes. Consistent with this, we did not see evidence of clonal expansions in the patients for up to 20 to 32 months after gene therapy.

Discussion: Our gene transfer protocol provided efficient stem cell transduction in vitro, resulting in robust and stable in vivo gene marking. WAS expression was restored to near-physiological levels in the patients, resulting in immunological and hematological improvement and clinical benefit. Clonal tracking of stem cell dynamics by vector insertions showed details of hematopoietic reconstitution after gene therapy. Comparison with clinical data from $\gamma$-retroviral gene therapy in the same disease setting strongly suggests that LV gene therapy offers safety advantages, but a longer follow-up time is needed for validation. Collectively, our findings support the use of LV gene therapy to treat patients with WAS and other hematological disorders.

Analysis of common insertion sites (CIS) in gene therapy trials using lentiviral versus $\gamma$-retroviral vectors. Word clouds show the intensity of insertion sites clustering in each of the CIS genes (the larger the gene name, the larger the number of insertion sites within or in the proximity of that gene). The names of the CIS genes detected in both gene therapy trials are reported at the intersection between the circles.
READ THE FULL ARTICLE ONLINE http://dx.doi.org/10.1126/science.1233151

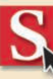

Cite this article as A. Aiuti et al. Science 341, 1233151 (2013). DOI: $10.1126 /$ science. 1233151

\section{FIGURES AND TABLE IN THE FULL ARTICLE}

Fig. 1. Engraftment of transduced cells and WASP expression after gene therapy.

Fig. 2. Clinical features and immune function of WAS patients after gene therapy.

Fig. 3. Long-term polyclonal engraftment of gene-corrected HSPC, assessed by longitudinal integration site profiling.

Fig. 4. Multilineage engraftment and activity of gene-corrected HSPC.

Fig. 5. Comparative analysis of vector integration sites in patients treated by gene therapy with lentiviral or $\gamma$-retroviral vectors.

Fig. 6. Common insertion sites and oncogenic hits in lentiviral versus $\gamma$-retroviral gene therapy.

Table 1. Characteristics and treatment of the three WAS patients.

\section{SUPPLEMENTARY MATERIALS}

Supplementary Text

Figs. S1 to S46

Tables S1 to S25

References

\section{RELATED ITEMS IN SCIENCE}

A. Biffi et al., Lentiviral hematopoietic stem cell gene therapy benefits metachromatic

leukodystrophy. Science 341, 1233158 (2013); doi:10.1126/science. 1233158

I. M. Verma, Edging toward the promise of gene therapy. Science 341, 853-855 (2013); doi:10.1126/science.1242551

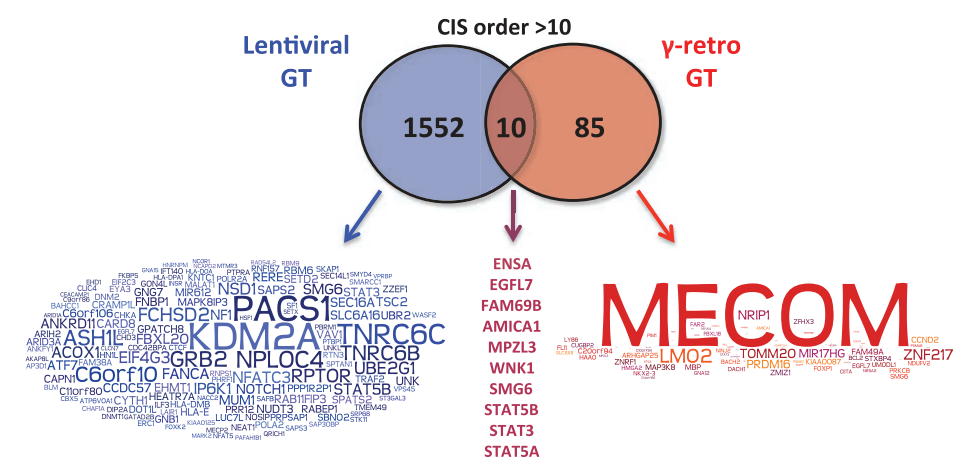




\section{Lentiviral Hematopoietic Stem Cell Gene Therapy in Patients with Wiskott-Aldrich Syndrome}

Alessandro Aiuti, ${ }^{1,2,3,4 *}$ Luca Biasco,${ }^{1} \dagger$ Samantha Scaramuzza, ${ }^{1} \dagger$ Francesca Ferrua, ${ }^{2,3,5}$ Maria Pia Cicalese, ${ }^{2,3}$ Cristina Baricordi, ${ }^{1}$ Francesca Dionisio, ${ }^{1}$ Andrea Calabria, ${ }^{1}$ Stefania Giannelli, ${ }^{1}$ Maria Carmina Castiello, ${ }^{1,5}$ Marita Bosticardo, ${ }^{1}$ Costanza Evangelio, ${ }^{2,3}$ Andrea Assanelli, ${ }^{3,6}$ Miriam Casiraghi, ${ }^{2}$ Sara Di Nunzio, ${ }^{2}$ Luciano Callegaro, ${ }^{2}$ Claudia Benati, ${ }^{7}$ Paolo Rizzardi, ${ }^{7}$ Danilo Pellin, ${ }^{8}$ Clelia Di Serio, ${ }^{8}$ Manfred Schmidt, ${ }^{9}$ Christof Von Kalle, ${ }^{9}$ Jason Gardner, ${ }^{10}$ Nalini Mehta, ${ }^{11}$ Victor Neduva, ${ }^{11}$ David ]. Dow, ${ }^{11}$ Anne Galy, ${ }^{12}$ Roberto Miniero, ${ }^{13}$ Andrea Finocchi, ${ }^{4}$ Ayse Metin, ${ }^{14}$ Pinaki P. Banerjee, ${ }^{15}$ Jordan S. Orange, ${ }^{15}$ Stefania Galimberti, ${ }^{16}$ Maria Grazia Valsecchi, ${ }^{16}$ Alessandra Biffi, ${ }^{1,2,3}$ Eugenio Montini, ${ }^{1}$ Anna Villa, ${ }^{1,17}$ Fabio Ciceri, ${ }^{3,6}$ Maria Grazia Roncarolo, ${ }^{1,2,3,5} \ddagger$ Luigi Naldini ${ }^{1,5} \ddagger$

Wiskott-Aldrich syndrome (WAS) is an inherited immunodeficiency caused by mutations in the gene encoding WASP, a protein regulating the cytoskeleton. Hematopoietic stem/progenitor cell (HSPC) transplants can be curative, but, when matched donors are unavailable, infusion of autologous HSPCs modified ex vivo by gene therapy is an alternative approach. We used a lentiviral vector encoding functional WASP to genetically correct HSPCS from three WAS patients and reinfused the cells after a reduced-intensity conditioning regimen. All three patients showed stable engraftment of WASP-expressing cells and improvements in platelet counts, immune functions, and clinical scores. Vector integration analyses revealed highly polyclonal and multilineage haematopoiesis resulting from the gene-corrected HSPCs. Lentiviral gene therapy did not induce selection of integrations near oncogenes, and no aberrant clonal expansion was observed after 20 to 32 months. Although extended clinical observation is required to establish long-term safety, lentiviral gene therapy represents a promising treatment for WAS.

$\mathrm{W}$ iskott-Aldrich syndrome (WAS) is an $\mathrm{X}$-linked primary immunodeficiency characterized by infections, micro-

\begin{abstract}
${ }^{1}$ San Raffaele Telethon Institute for Gene Therapy (HSR-TIGET), Division of Regenerative Medicine, Stem Cells, and Gene Therapy, San Raffaele Scientific Institute, 20132 Milan, Italy. ${ }^{2}$ HSRTIGET Pediatric Clinical Research Unit, San Raffaele Scientific Institute, 20132 Milan, Italy. ${ }^{3}$ Pediatric Immunohematology and Bone Marrow Transplant Unit, San Raffaele Scientific Institute, 20132 Milan, Italy. ${ }^{4}$ University Department of Pediatrics (DPUO) Bambino Gesù Children's Hospital and Tor Vergata University, School of Medicine, 00165 Rome. ${ }^{5}$ Vita-Salute San Raffaele University, 20132 Milan, Italy. ${ }^{6}$ Hematology and Bone Marrow Transplant Unit, San Raffaele Scientific Institute, 20132 Milan, Italy. ${ }^{7}$ MolMed S.p.A., 20132 Milan, Italy. ${ }^{8}$ University Centre of Statistics in the Biomedical Sciences (CUSSB), Vita-Salute San Raffaele University, 20132 Milan, Italy. ${ }^{9}$ Nationales Zentrum für Tumorerkrankungen (NCT), Deutsches Krebsforschungszentrum (DKFZ), 69120 Heidelberg, Germany. ${ }^{10}$ Regenerative Medicine Discovery Performance Unit, GlaxoSmithKline Research and Development, King of Prussia, 19406 PA, USA. ${ }^{11}$ Molecular and Cellular Technologies, GlaxoSmithKline, Stevenage Herts SG1 2NY, UK. ${ }^{12}$ Unité Mixte de Recherche (UMR) 951, Molecular Immunology and Biotherapies, Genethon, 91002 Evry, France. ${ }^{13}$ Dipartimento di Scienze Mediche e Chirurgiche, Università Magna Graecia di Catanzaro, 88100 Catanzaro, Italy. ${ }^{14}$ Ankara Children's Hospital, 06050 Ankara, Turkey. ${ }^{15}$ Texas Children's Hospital, Baylor College of Medicine, Houston, TX 73030, USA ${ }^{16}$ Dipartimento di Medicina Clinica e Prevenzione, University of Milano-Bicocca, 20126 Monza, Italy. ${ }^{17}$ Istituto di Ricerca Genetica e Biomedica (IRGB)-Consiglio Nazionale delle Ricerche (CNR), 20138 Milan, Italy.
\end{abstract}

*Corresponding author. E-mail: aiuti.alessandro@hsr.it $\dagger$ These authors contributed equally to this work. $\ddagger$ These authors contributed equally to this work. thrombocytopenia, eczema, autoimmunity, and lymphoid malignancies $(1,2)$. The disorder is caused by mutations in the WAS gene, which codes for WASP, a protein that regulates the cytoskeleton. WASP-defective immune cells display alterations in proliferative responses after activation, cell migration, immunological synapsis formation, and cytotoxicity (3-5). Allogeneic hematopoietic stem/progenitor cell (HSPC) transplantation can be curative, but it is often associated with substantial morbidity and mortality, particularly in the absence of fully matched donors (6-8).

For patients without matched donors, an alternative therapeutic strategy is the infusion of autologous HSPCs that have been genetically corrected ex vivo. This gene therapy approach has been successful in more than 50 patients affected by primary immunodeficiencies, including 10 WAS patients treated with HSPCs transduced with a $\gamma$-retroviral vector encoding a functional WAS gene (9-15). Gene therapy combined with a reduced intensity conditioning regimen proved to be effective and safe in patients with severe combined immunodeficiency (SCID) due to adenosine deaminase (ADA) deficiency, who were followed up to 13 years after treatment $(9,15,16)$. In contrast, despite the initial clinical benefit, gene therapy with $\gamma$-retroviral-transduced HSPC was associated with the development of leukemia or myelodysplasia in patients with SCID-X1, chronic granulomatosis disease, and WAS (14, 17-20). These adverse events were ascribed to vector insertion sites (ISs) near specific proto-oncogenes, leading to their transactivation by enhancer/promoter sequences within the long-terminal repeat (LTR) of the retroviral vector $(10-12,21-23)$. In the case of WAS, characterization of ISs over the first 2 years of followup revealed a highly skewed insertion profile in vivo, resulting in the expansion of clones with insertions in proto-oncogenes such as LMO2 (12), some of which progressed to leukemias $(14,24)$. The possibility of vector-driven leukemogenesis is a particular concern for WAS patients, who are cancer-prone (1).

Lentiviral vectors with self-inactivating (SIN) LTRs integrate efficiently in HSPC, allow robust transgene expression from a promoter of choice inserted within the vector, and could potentially be safer for gene therapy applications (24-26). Lentiviral-based HSPC gene therapy combined with full conditioning has been used to treat three patients with adrenoleukodystrophy (ALD) (27) and one patient with $\beta$-thalassemia (28), resulting in 10 to $15 \%$ progenitor cell marking with therapeutic benefit. Although a relative expansion of a clone harboring an insertion in the HMGA2 gene was observed in the $\beta$-thalassemia patient (28), no aberrant clonal proliferation has been reported for the lentiviral-based trials up to 5 years after treatment $(27,29)$.

We developed a SIN lentiviral vector coding for human WASP under the control of a 1.6-kb reconstituted WAS gene promoter (LV-w1.6W) (3). The use of this endogenous promoter ensures that the transgene is expressed in a physiological manner (4), restoring WASP expression and function in human and murine WAS cells $(3,30-34)$. Its moderate enhancer activity combined with the SIN LTR design reduces the risk of insertional mutagenesis (35), as shown by in vitro transformation assays (36) and preclinical in vivo studies in WASP-deficient mice $(34,37)$. These data provided the rationale for a phase I/II clinical trial in which LV-w1.6W was used as a gene therapy vector for treatment of patients with WAS (38).

Results

Lentiviral Transduction of HSPC and Infusion of Gene-Corrected Cells into Patients Pretreated with Reduced Intensity Conditioning

Three children with WAS, who had been shown by genotyping to carry severe mutations in the $\mathrm{X}$-linked WAS gene and who did not have compatible allogeneic donors, were enrolled in the phase I/II clinical trial (Table 1). All patients suffered from recurrent infections, eczema, bleeding, and thrombocytopenia, with a disease score ranging from 3 to 4 (39) (Table 1). Autologous bone-marrow $(\mathrm{BM})$-derived $\mathrm{CD} 34^{+}$cells were collected, transduced twice with purified LV-w1.6W vector using an optimized protocol (fig. S1) (34), and reinfused intravenously back into the patients 3 days after collection. The vector and genetically modified 
cells were characterized extensively for quality and safety (tables S1 to S3 and figs. S1 and S2).

Vector-specific quantitative real-time fluorescence polymerase chain reaction (qPCR) on individually collected colony-forming cells (CFC) revealed high gene transfer efficiency-i.e., 88 to $100 \%$. Average vector copy number (VCN) per genome measured in bulk-cultured $\mathrm{CD} 34^{+}$cells was $2.3 \pm 0.6$ (Table 1). WASP expression in the transduced $\mathrm{CD} 34^{+}$cells was confirmed by immunoblotting (fig. S3). Before HSPC reinfusion, patients received a reduced-intensity conditioning regimen, consisting of monoclonal antibody $(\mathrm{mAb})$ to CD20 , busulfan [7.6 to $10.1 \mathrm{mg} / \mathrm{Kg}$ intravenous (i.v.), targeted for weight and pharmacokinetics], and fludarabine $\left(60 \mathrm{mg} / \mathrm{m}^{2}\right)$, designed to achieve considerable depletion of endogenous HSPC and immune cells with limited toxicity (see Materials and Methods). The mean infused $\mathrm{CD}^{+} 4^{+}$cell dose was $11.07 \pm 2.70 \times 10^{6}$ cells $/ \mathrm{kg}$ (Table 1 and table S4). No adverse reactions were observed after the infusions.

\section{Engraftment of Lentiviral-Transduced Cells and Restoration of WASP Expression}

All three WAS patients showed robust and multilineage engraftment of gene-corrected cells in $\mathrm{BM}$ and peripheral blood (PB), persisting up to the latest time point analyzed (30 months after gene therapy). Gene-marking in PB granulocytes peaked in the first month after treatment and then stabilized at a VCN range of 0.4 to 0.9 (Fig. 1A). Similar marking levels were seen in PB monocytes (Fig. 1A), as well as in granulocytic and megakaryocytic cells, CD34 ${ }^{+}$cells (Fig. 1B), and erythroid cells (fig. S4) collected from the BM. The in vivo engraftment of lentiviraltransduced HSPC was confirmed throughout the follow-up and persisted at high levels [patient 1 (Pt1), 34\%; Pt2, 26\%; Pt3, 48\%) 1 year after treatment, as shown by vector-specific $\mathrm{PCR}$ on BM CFC (Fig. 1C). Based on these data, we estimated that each transduced progenitor cell contained on average 1 to 1.6 copies of the vector. Transduced B and natural killer (NK) cells were detectable 1 month after gene therapy and increased over time, with PB-derived B cells showing VCN higher by a factor of 1.5 to 2 as compared with BM B cells (Fig. 1, A and B). Transduced T cells appeared 3 to 6 months after gene therapy and reached the highest VCN as compared with other lineages (VCN range 1.0 to 2.4) (Fig. 1A).

WASP expression, as measured by flow cytometry, progressively increased over time in PB lymphocytes and platelets in all three patients (Fig. 1D). WAS protein was present in a large proportion of $\mathrm{T}$ cells $\left(\mathrm{CD} 4^{+}\right.$and $\left.\mathrm{CD} 8^{+}\right), \mathrm{NK}$ cells, and monocytes at mean expression level comparable to normal donors, whereas in $\mathrm{B}$ cells and platelets its expression level was lower than in controls (fig. S5). Interestingly, the proportion of WASP ${ }^{+}$ cells was higher in PB-derived platelets as compared with their BM-derived counterparts (fig. S6), suggesting a preferential migration or selec- tive survival advantage of gene-corrected platelets in the periphery.

\section{Clinical and Immunological Improvement After Gene Therapy}

All treated children are clinically well with posttreatment follow-up of 20 to 32 months (Table 1). After conditioning, patients experienced severe neutropenia (neutrophil counts $<500 / \mu 1$ ) lasting from 12 to 19 days, followed by normalization of neutrophil counts. None of the patients experienced mucositis or other chemotherapy-related toxicity. Serious adverse events occurred in Pt 2 and Pt3 within the first 2 to 6 months of gene therapy. These events were mainly of infectious origin, likely favored by the underlying clinical conditions and immune deficiency typical of the early posttransplant period. Both patients fully recovered from them (see Materials and Methods). No abnormal cellular expansion was detected in $\mathrm{BM}$ and $\mathrm{PB}$ by immunophenotypic, morphologic, and karyotypic analyses. Assays to detect antibodies to HIV Gag p24 and replication-competent lentivirus in patients' blood were negative at all times of analysis.

In all three children, symptoms of WAS showed substantial improvement. Pretreatment eczema resolved between 6 and 12 months after gene therapy

Table 1. Characteristics and treatment of the three WAS patients. WASP expression analysis was performed on PB lymphocytes by FACS. Patient 1 also received G-CSF mobilized peripheral blood (MPB)derived $\mathrm{CD}_{3}{ }^{+}$cells, previously collected as back-up, to achieve the target HSPC dose. A\&W, alive and well; CMV, cytomegalovirus; ENT, ear, nose, throat; Gl, gastrointestinal; GE, gastroesophageal; HHV-6, human herpes virus type 6; HSV, herpes simplex virus; IVIG, intravenous immunoglobulins; URTI, upper respiratory tract infection; UTI, urinary tract infection; VZV, Varicella zoster virus.

\begin{tabular}{|c|c|c|c|}
\hline & Patient 1 & Patient 2 & Patient 3 \\
\hline $\begin{array}{l}\text { Infectious } \\
\text { manifestations }\end{array}$ & Recurrent ENT & $\begin{array}{l}\text { Pneumonias, colitis } \\
\text { arthritis/cellulitis, } \\
\text { URTI, UTI }\end{array}$ & $\begin{array}{l}\text { Pneumonia with } \\
\text { respiratory distress, } \\
\text { URTI, otitis }\end{array}$ \\
\hline Pathogens & VZV, CMV, HSV, EBV & CMV, HHV-6, candida & Pneumocystis jirovecii, CMV \\
\hline $\begin{array}{l}\text { Thrombocytopenia } \\
\text { manifestations }\end{array}$ & Skin petechiae & $\begin{array}{l}\text { Skin petechiae, } \\
\text { Gl bleeding }\end{array}$ & $\begin{array}{l}\text { Skin petechiae, } \\
\text { Gl bleeding, epistaxis }\end{array}$ \\
\hline Eczema & Moderate-severe & Moderate-severe & Severe \\
\hline Other & $\begin{array}{l}\text { Developmental } \\
\text { disorder, allergy }\end{array}$ & $\begin{array}{l}\text { Failure to thrive, } \\
\text { elevated inflammatory } \\
\text { indexes/vasculitis, } \\
\text { hepatosplenomegaly }\end{array}$ & $\begin{array}{l}\text { GE reflux/food } \\
\text { aversion (fed by } \\
\text { nasogastric } \\
\text { tube), allergy }\end{array}$ \\
\hline WAS mutation & $\begin{array}{l}\text { Exon 10: C>T } \\
995(\mathrm{R} 321 \mathrm{X})\end{array}$ & IVS10del11nt & $37 \mathrm{C}>\mathrm{T}(\mathrm{R} 13 \mathrm{X})$ \\
\hline WASP expression & $<5 \%$ & $<5 \%$ & $<5 \%$ \\
\hline Zhu score & 3 & 4 & 4 \\
\hline $\begin{array}{l}\text { Age at treatment } \\
\text { (years) }\end{array}$ & 5.9 & 1.6 & 1.1 \\
\hline $\begin{array}{l}\text { Infused CD34 } 4^{+} \text {cells } \\
\quad\left(\times 10^{6} / \mathrm{kg}\right)\end{array}$ & $3.66(\mathrm{BM})+5.25$ (MPB) & 14.1 & 10.2 \\
\hline $\begin{array}{l}\text { Vector } \\
\text { copies/genome }\end{array}$ & $1.9(\mathrm{BM})-1.4(\mathrm{MPB})$ & 2.4 & 2.8 \\
\hline $\begin{array}{l}\text { Transduction } \\
\text { efficiency (CFC) }\end{array}$ & $92 \%(B M)-88 \%(M P B)$ & $97 \%$ & $100 \%$ \\
\hline $\begin{array}{l}\text { Follow-up } \\
\text { (months) }\end{array}$ & 32 & 23 & 20 \\
\hline $\begin{array}{l}\text { Current clinical } \\
\text { conditions }\end{array}$ & $\begin{array}{l}\text { A\&W, no eczema, } \\
\text { no major bleeding or } \\
\text { petechiae, off IVIG }\end{array}$ & $\begin{array}{l}\text { A\&W, no eczema, } \\
\text { no major bleeding } \\
\text { or petechiae }\end{array}$ & $\begin{array}{l}\text { A\&W, no eczema, } \\
\text { no major bleeding } \\
\text { or petechiae }\end{array}$ \\
\hline
\end{tabular}

and did not recur (Table 1). Beginning 6 months after gene therapy, the frequency and severity of infections progressively decreased, and cytomegalovirus replication was well-controlled, allowing withdrawal of anti-infectious prophylaxis in Pt1 and Pt3. Pt1 discontinued i.v. immunoglobulin supplementation 6 months after gene therapy, with positive antibody responses after vaccination.

Platelet counts improved significantly during the first year after gene therapy (Fig. 2A), as assessed by a mixed linear model applied to the serially repeated sampling $(P=0.03)$. Although these counts never reached normal values, the platelet volumes normalized after gene therapy (mean platelet volume range, 8.3 to $9.2 \mathrm{fl}$; normal values, 7.4 to $10.9 \mathrm{fl}$ ). After discontinuation of platelet transfusions (1 to 7 months after gene therapy), none of the patients experienced bleeding or skin manifestations of thrombocytopenia, with the exception of occasional grade 1 gastrointestinal bleeding in Pt2 (Fig. 2B). Moreover, all patients tested negative for a large panel of autoantibodies 1 year after gene therapy. The overall clinical improvement resulted in a reduced disease severity score in all patients (Fig. 2C).

Lymphocyte subpopulation counts decreased after the conditioning regimen but progressively 
returned to normal levels for age within 6 to 12 months after treatment (fig. S7). In all patients, proliferative responses to $\mathrm{mAb}$ to $\mathrm{CD} 3$ increased after treatment and reached the range of agematched controls (Fig. 2D). Similarly, the proliferative capacity of $\mathrm{T}$ cell lines from Pt1 and Pt3 greatly improved after gene therapy (fig. S8). T cell receptor (TCR) V $\beta$ profiling revealed that all three WAS patients displayed a broader polyclonal repertoire after gene therapy, in agreement with the polyclonal reconstitution observed by IS analysis (see below) (fig. S9).

Because regulatory $T\left(\mathrm{~T}_{\text {reg }}\right)$ cell function is defective in WAS patients $(32,40)$, we evaluated the suppressive ability of $\mathrm{T}_{\text {reg }}$ cells (VCN, 1.37) sorted from Pt1. As shown in Fig. 2E, the in vitro suppressive function of $\mathrm{T}_{\text {reg }}$ cells was restored after gene therapy. This is consistent with the finding that $\mathrm{CD}^{+} / \mathrm{CD} 25^{\text {high }}$ cells from both Pt1 and Pt3 express WASP after gene therapy (fig.
S10). It is known that WASP-deficient NK cells show an altered immune function (41). We found that WASP-expressing, but not WASP-deficient, NK cells isolated from Pt1 after gene therapy functioned normally in immunological synapse formation (Fig. 2F and fig. S11). The improved NK cell function of all three patients resulted in normal cytotoxic activity after gene therapy (Fig. 2G).

\section{Multilineage and Polyclonal Engraftment of Gene-Corrected HSPC, Assessed by Longitudinal Integration Site Profiling}

To monitor the clonal contribution of genecorrected cells to hematopoiesis in the three patients, we performed a high-throughput IS analysis $(42,43)$ on multiple lineages and time points up to 18 months after infusion of transduced HSPCs (see Supplementary Text, figs. S12 to S46, and tables S8 to S25). Linear amplificationmediated (LAM) PCR and next-generation sequenc- ing $(42,43)$ detected $>2,400,000$ IS sequences that were mapped to 33,363 unique chromosomal positions in the patients: 11,137 from Pt1, 10,889 from Pt2, and 10,337 from Pt3.

The relative proportion of sequencing reads corresponding to each specific IS, as collected from BM CD $34^{+}$cells and $\mathrm{PB}$ myeloid $\mathrm{B}$ and $\mathrm{T}$ cells, was used as a surrogate of clonal repertoire of gene-corrected cells and safety readout (Fig. 3 and figs. S12 to S14). We found that, beginning 1 month after gene therapy, the vast majority of ISs from all lineages and time points were well below $5 \%$, with a few occasionally reaching up to 15 to $20 \%$ of the total reads retrieved from a lineage (Fig. 3A). By monitoring the most frequent ISs in each lineage, we found that highly represented insertion sites were different at each time point and fluctuated over time for up to 6 to 12 months after gene therapy (Fig. 3B). At later time points, in line with the stabilization of
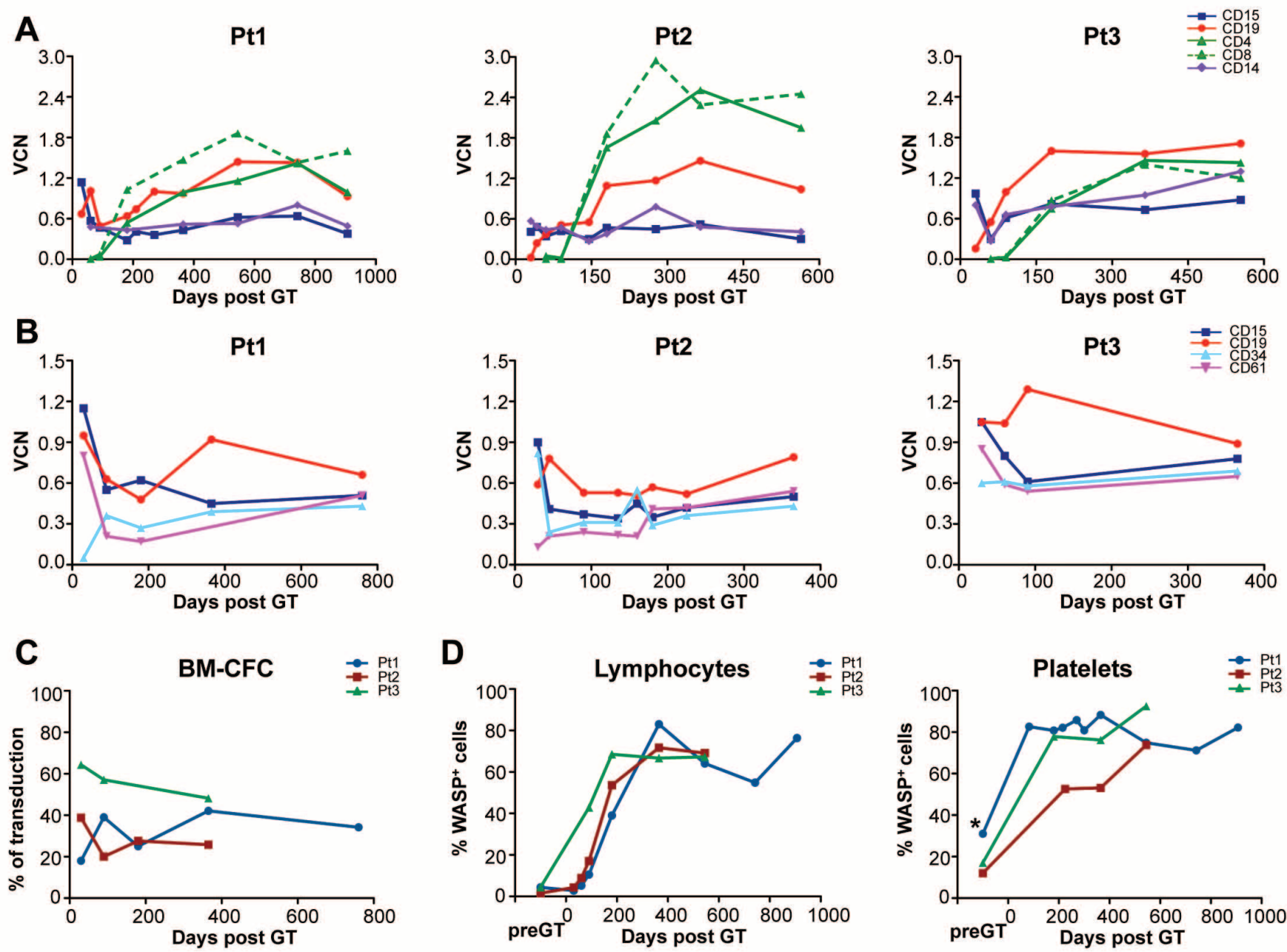

Fig. 1. Engraftment of transduced cells and WASP expression after gene therapy. VCN per genome was evaluated by $\mathrm{qPCR}$ at different time points (up to 2.5 years) after gene therapy (GT) in $\mathrm{CD} 15^{+}$granulocytes, $\mathrm{CD} 19^{+}$ $\mathrm{B}$ cells, $\mathrm{CD} 4^{+}$and $\mathrm{CD} 8^{+} \mathrm{T}$ cells, $\mathrm{CD} 14^{+}$monocytes, $\mathrm{CD} 34^{+}$progenitors, and $\mathrm{CD} 1^{+}$(megakaryocytic lineage), purified either from peripheral blood (A) or bone marrow (B) in Pt1 (left), Pt2 (center) and Pt3 (right). (C) Percentage of vector-positive BM CFC evaluated by PCR analyses on individual colonies derived from ex vivo purified CD34 ${ }^{+}$cells after gene therapy. (D) WAS protein expression measured by cytofluorimetric analysis at different time points after gene therapy in patient lymphocytes (left) and platelets (right). *, In Pt1, WASP expression was measured after transfusion of donor platelets. Transgene expression was confirmed by immunoblot analysis of peripheral blood mononuclear cells, untransformed T-cell lines, and a EBV-transformed B cell line (fig. S3). 
hematopoietic output, we detected a persistent multilineage contribution of several ISs, some of which were highly represented (Fig. 3B), but remained below $10 \%$ of all the reads belonging to ISs retrieved from the PB cells in the 1-year interval (Fig. 3A and fig. S14). It is possible that HSPC activity in Pt 2 was affected by the occurrence of bacterial sepsis 6 months after gene therapy. At that time, a group of ISs marking T cells, B cells, and myeloid cells became relatively more abundant, possibly revealing the stress-induced activation of a limited pool of progenitors.

The Shannon diversity index was used to assess the overall clonal repertoire composition of in vivoderived $\mathrm{BM} \mathrm{CD} 34^{+}$and myeloid cells. In the first months after treatment, clonal diversity was lower then measured in the in vitro-transduced cell pop- ulation but later increased and stabilized at 12 to 18 months (Fig. 3C). As predicted by the slower dynamics of thymic reconstitution, $T$ cells showed different kinetics with increasing diversity from 3 to 6 months and stabilization to levels similar to other lineages at 9 to 18 months after gene therapy.

We next compared ISs retrieved from BM CD $34^{+}$cells, myeloid, and lymphoid lineages in each patient, applying stringent analytical filters to take into account sample impurity and crosscontaminations. This analysis unveiled a group of ISs that was shared among these data sets (Fig. 4A). The shared ISs in CD34 ${ }^{+}$cells and myeloid/lymphoid lineages increased from 18.2 to $27.2 \%$ at 1 year after gene therapy in Pt1. A higher proportion of integrations shared with other lineages (44.1\%) was detected in BM CFC from Pt1. A substan- tial fraction of the ISs retrieved from $\mathrm{BM} \mathrm{CD} 34^{+}$ cells or CFC at 1 year after gene therapy (Fig. 4B) could be traced back to earlier follow-up samples of mature cells, pointing to the efficient engraftment of self-renewing gene-marked HSPCs.

Our data allowed an estimation of the number of transduced HSPCs contributing to hematopoiesis in vivo. Vector integrations were analyzed in two independent samplings (12 and 18 months after gene therapy) of purified PB myeloid cells, which are short-lived and provide a readout of stem cell output. Using the Petersen/Schnabel model estimator of population size (44), we calculated a theoretical minimal number of about 6300 and 1700 transduced active stem cells in Pt1 and Pt2, respectively (table S25), which corresponds to about 1.5 to 2.5 in $1 \times 10^{5}$ infused CD $34^{+}$cells.
A

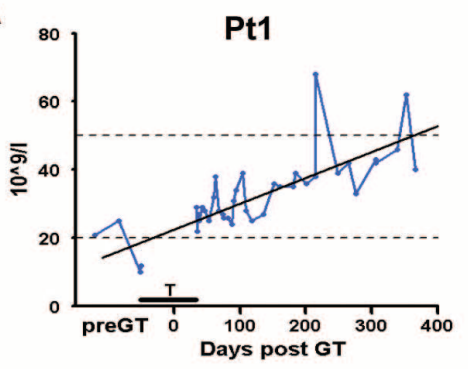

B

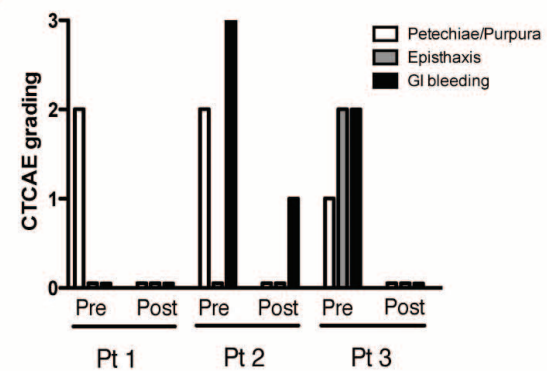

E

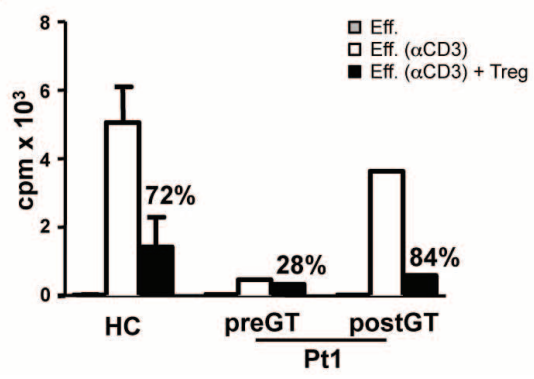

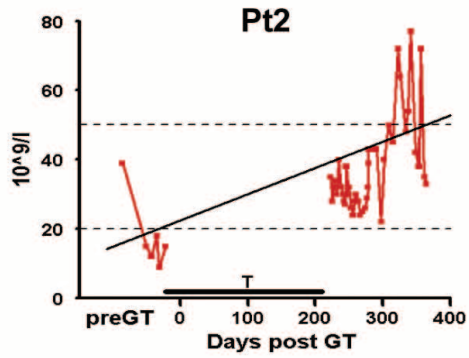

C

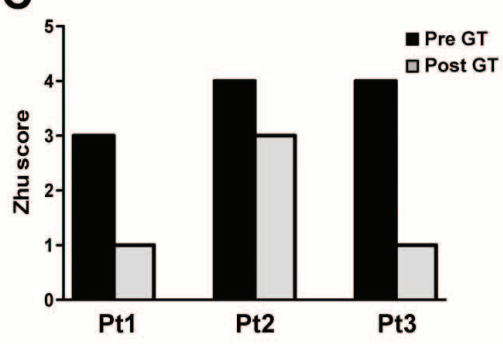

$\mathbf{F}$

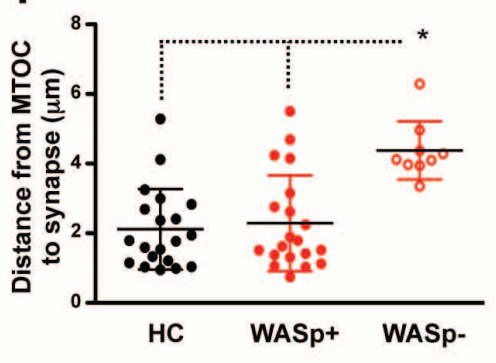

Pt3

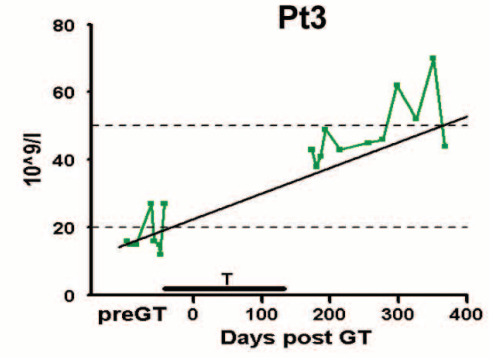

$\mathbf{D}_{10}$

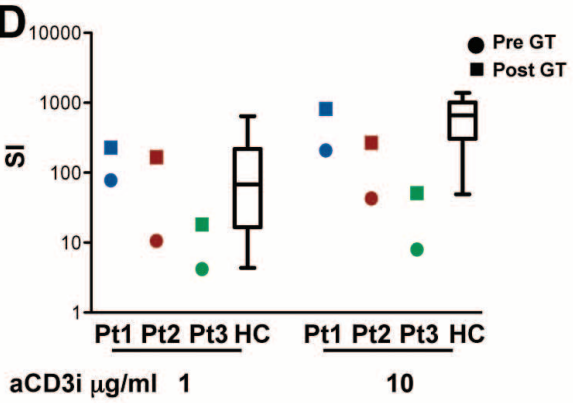

G

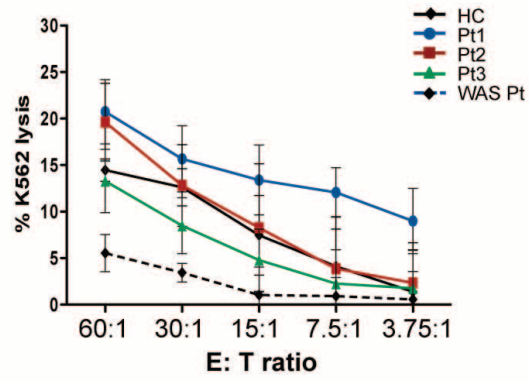

Fig. 2. Clinical features and immune function of WAS patients after gene therapy. (A) Platelet counts before and 1 year after gene therapy. Kinetics of platelet counts during the first year of follow-up, analyzed by a mixed linear model applied to the individual repeated counts. Platelet transfusions ( $T$ ) are indicated by a horizontal bar. (B) Summary of bleeding events. Each of the three categories [skin manifestations (petechiae/purpura), epistaxis, and GI bleeding] was given a maximum grading, according to Common Terminology Criteria for Adverse Events (CTCAE) (v3.0). Patients were evaluated at 1 year after gene therapy following discontinuation of platelet transfusions (see Materials and Methods). (C) Disease score (Zhu score) evaluated pre- and 1 year post-gene therapy (39). (D) TCR-driven proliferation in PB mononuclear cells from WAS patients (before and 1 year after gene therapy) or healthy controls (HCs). (Boxplot) Mean, first, and fourth quartile, 5th and 95th percentile; $n=15$ subjects. SI, stimulation index. (E)

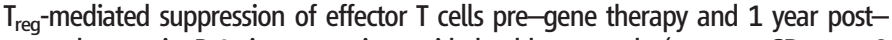
gene therapy in Pt1, in comparison with healthy controls (mean $\pm S D, n=9$ subjects). Eff, unstimulated effector cells. Eff.(a-CD3), effector cells stimulated with allogeneic accessory cells and soluble mAb to CD3. $\mathrm{T}_{\text {reg }}$ cells (sorted for $\mathrm{CD}^{+} /$ $\mathrm{CD} 25^{\text {high }} / \mathrm{CD} 127^{\text {low/neg }}$ cells), were added to effector cells at a 1:1 ratio, and proliferation was measured by ${ }^{3} \mathrm{H}$-thymidine incorporation. Percentages indicate inhibition of proliferation. (F) Formation of NK immunological synapse. Distance of the microtubule organizing center (MTOC) from the immunological synapses in NK cells contacting K562 target cells. Analyses were performed by confocal microscopy in Pt1 18 months after gene therapy. Patient NK cells were identified as positive or negative for WASP expression by antibody to WASP. (G) NK cell cytotoxic activity. Shown is the percentage of lysis of $\mathrm{K} 562$ human erythroleukemia cells by patientderived PB mononuclear cells, as measured in a chromium-release assay. 
Comparison of Lentiviral Versus $\gamma$-Retroviral "Integrome" in Gene Therapy of WAS

We compared the integration profile of LV-w1.6W vector with 11,294 unique ISs retrieved from two WAS patients enrolled in the $\gamma$-retroviral gene therapy trial (12) collected over a similar time frame and analyzed through the same mapping pipeline to obtain a comparable data set (table $\mathrm{S} 10)$. The genomic insertional pattern of LV-w1.6W vector was similar in all three patients and fit the classical distribution of lentivirus showing a strong tendency to integrate within transcriptional units (fig. S15B) and cluster in gene-rich regions (Fig. 5A and fig. S15, A and B). No major difference was observed in the genomic distribution of LV-w1.6W
Fig. 3. Long-term polyclonal engraftment of gene-corrected HSPC, assessed by longitudinal integration site profiling. (A) Distribution of sequence reads in different lineages at different time points. Each boxplot shows the distribution of sequence reads in two WAS patients in the different lineages. Percentages of sequence reads for each IS are calculated over the total number of sequence reads from the same source (BM or PB) and time point. The $x$ axis indicates months after gene therapy; the $y$ axis shows percentage of sequence reads. IS outliers (over 95th percentile of IS data set from same time point) are shown as dots. The total number of ISs is shown on top of each boxplot for the relative lineage and time point. Genes proximal to IS representing more than $5 \%$ of sequence reads from the same source and time point are reported on top of outlier dots. (B) Top-contributing ISs inside each lineage in $\mathrm{BM} \mathrm{CD} 34^{+}$cells, PB myeloid, $B$ and $T$ cells in two WAS patients. Percentages of sequence reads for each IS are calculated over the total number of sequence reads from the same lineage. Top IS shown in the heat maps account for more than $5 \%$ of sequence reads from their lineage. Each column corresponds to a time point (months after gene therapy), and each row to a given top IS based on sequence reads. Color intensity on the heat maps represents for each IS the percentages of relative sequence reads on total sequence reads from the same lineage and time point, ranging from white (IS not detected at that time point) to gray (IS detected at percentages lower than $5 \%$ of sequence reads from that time point) to gradient of colors (IS

B
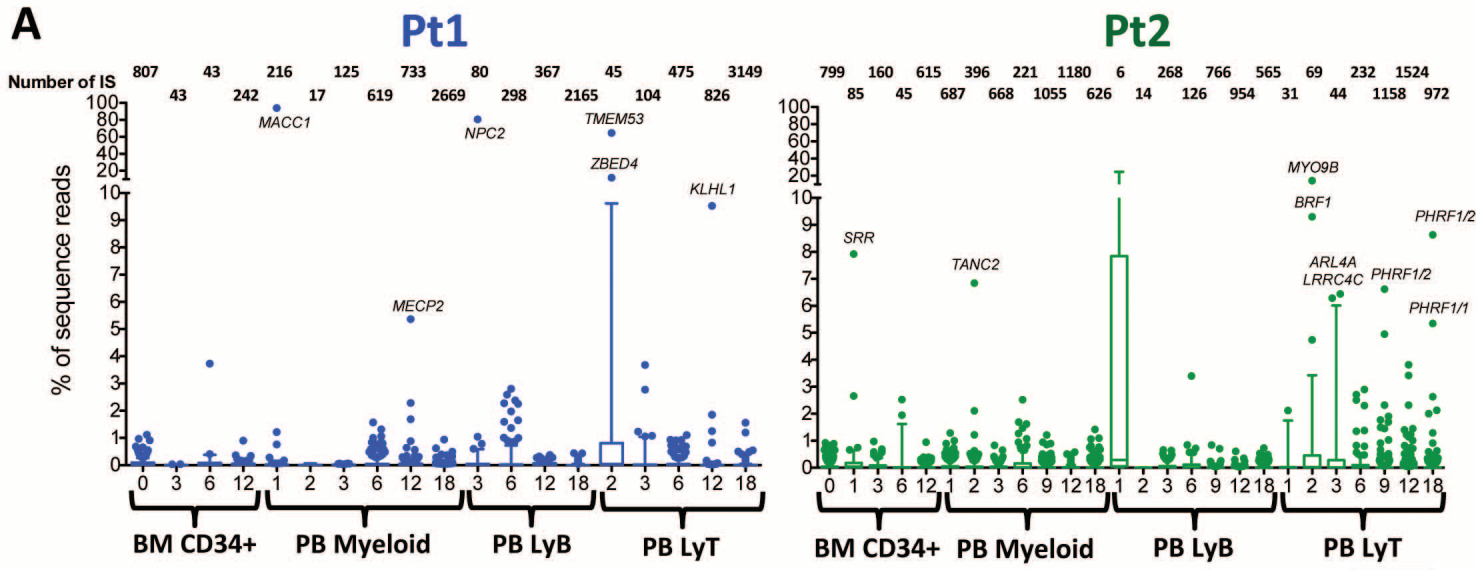

Months after GT
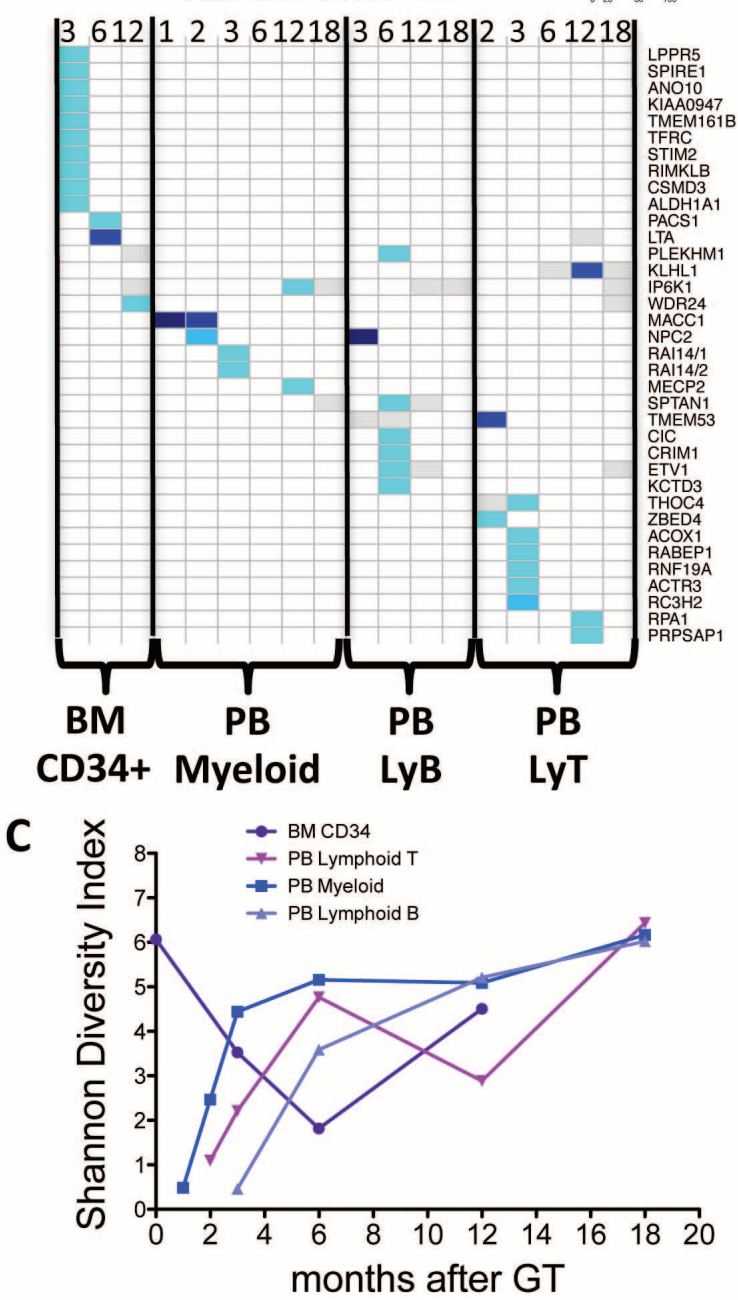

Months after GT
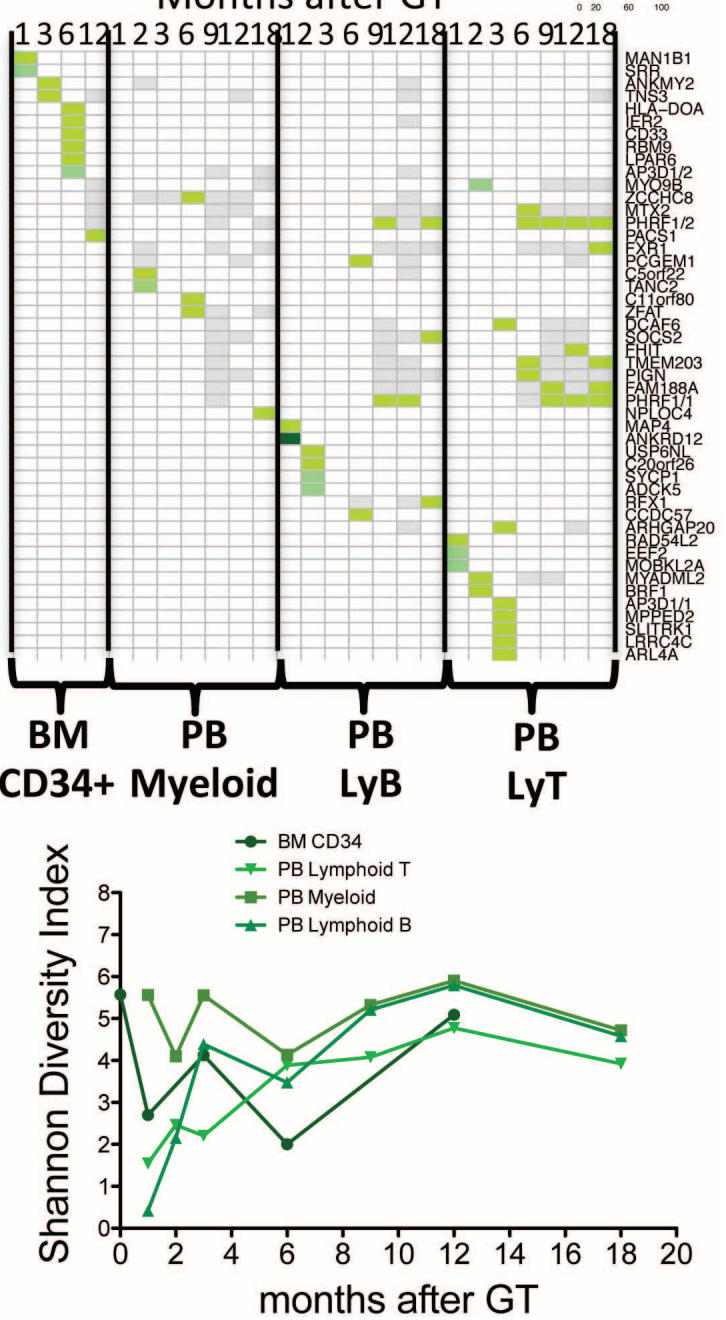

detected at more than $5 \%$ of sequence reads from that time point). (C) Diversity of ISs in different lineages and time points. For each IS data set from the same lineages and time points of (A) and (B), a Shannon diversity index was calculated and plotted. 
in the in vitro- versus patients-derived samples (fig. S16A). By contrast, the profile found in the cells from patients treated with $\gamma$-retroviral gene therapy was very different, showing a skewed profile toward transcription start sites (fig. S15A).

As reported in previous studies $(45,46)$, vector integration site selection could be influenced by the chromatin status of target cells during transduction and infection. Thus, we analyzed the density distribution of histone modifications mapped in $\mathrm{CD}_{3} 4^{+}$cells $(47)$ on a $100-\mathrm{kb}$ window surrounding the ISs from the two cohorts of patients (Fig. 5B and fig. S20). The probability density map showed that certain histone modifications were equally preferred ( $\mathrm{H} 3 \mathrm{~K} 4 \mathrm{me} 1)$ or avoided
(H3K9me3 and H3K27me3) by lentivirus and retrovirus integrations. In addition, no major differences were observed between in vitro and in vivo lentivirus data sets. By contrast, other chromatin features - such as H3K4me3, H3K36me3, and $\mathrm{H} 2 \mathrm{AZ}$, marking, respectively, transcription start sites, coding, and enhancer/promoter regions of actively expressed genes - were present at differential intensity around ISs of the two vectors (Fig. 5B). Of note, the concomitant low density of $\mathrm{H} 3 \mathrm{~K} 4 \mathrm{me} 3$ and $\mathrm{H} 2 \mathrm{AZ}$ seems to provide an optimal chromatin environment for lentivirus insertions (figs. S17 to S19) and help explain the different genomic distribution observed for retroviruses.
We also analyzed the ontological categories of the genes targeted by vector integration sites in the data sets from the two patient cohorts by using the GREAT (Genomic Regions Enrichment of Annotations Tool) software (48) (Fig. 5C). A broad spectrum of biological categories, including antigen presentation, response to virus, chromatin modification, and gene silencing, was represented among the lentivirus targeted genes. In contrast, the retroviral insertions were more often proximal to genes related to hematopoietic system maintenance, as well as to hematological diseases. Of note, the vast majority of gene categories targeted by ISs in our LV-w1.6W patients were also targeted in the previous ALD gene therapy trial (27) (figs. S21
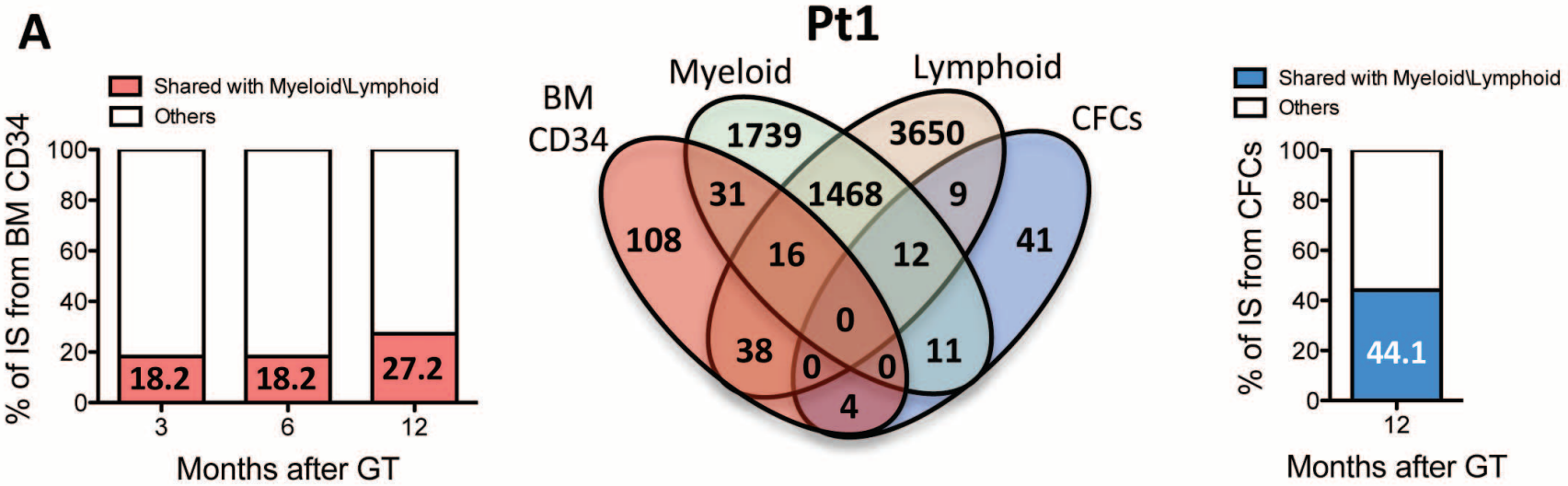

Months after GT
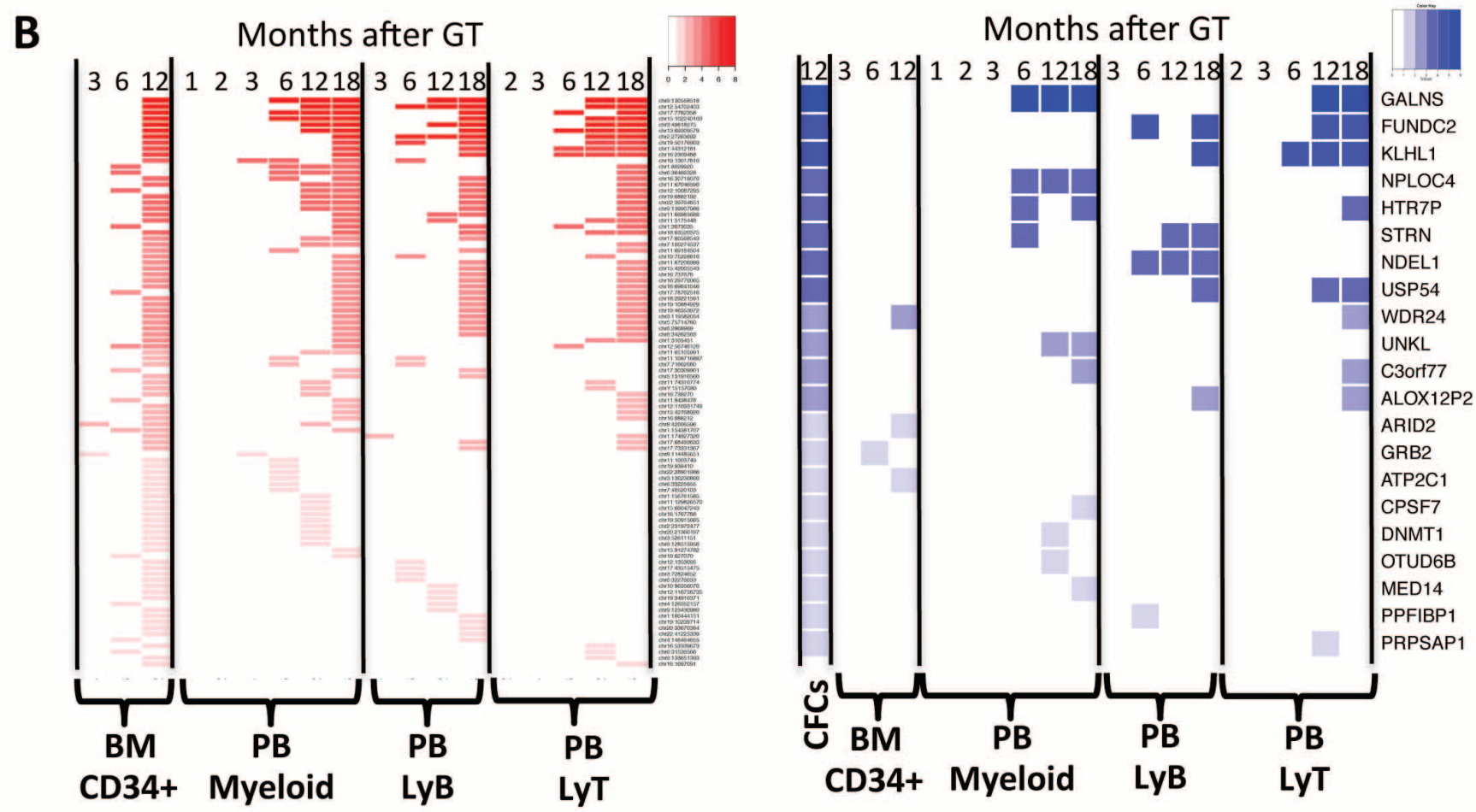

Fig. 4. Multilineage engraftment and activity of gene-corrected HSPC. (A) Multilineage detection of identical IS. Venn diagram show overlaps among $\mathrm{CD}^{+}{ }^{+}$, myeloid, lymphoid cells, and CFC IS data sets from Pt1. Column graphs show percentage of CD34 ${ }^{+}$cells and CFC IS from Pt1 shared with myeloidlymphoid lineages (red and blue portion of column, respectively) at different months after gene therapy. (B) Detection of shared ISs over time. Heat maps show CD34

cells and CFC IS at different time points shared with the four lineages of Fig. 3. Each column shows a lineage and a time point and each row a shared IS belonging to $\mathrm{CD} 34^{+}$cells (red) or CFC (blue). The intensity of colors indicates degree of IS detection in multiple lineages and time points from highly shared ISs (high intensity of red and blue) to ISs shared with a single lineage and time point (light red or blue). 

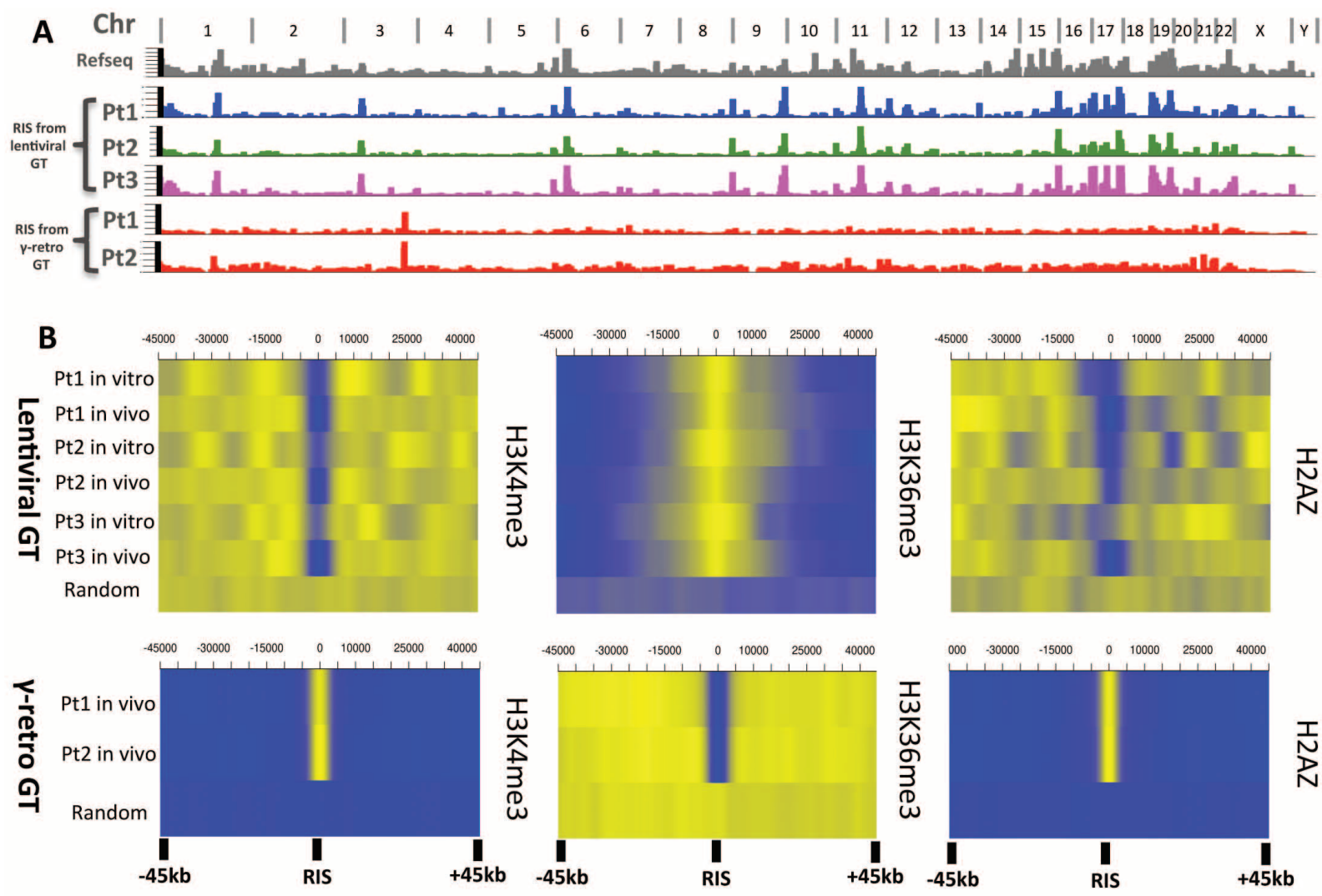

Biological process

C

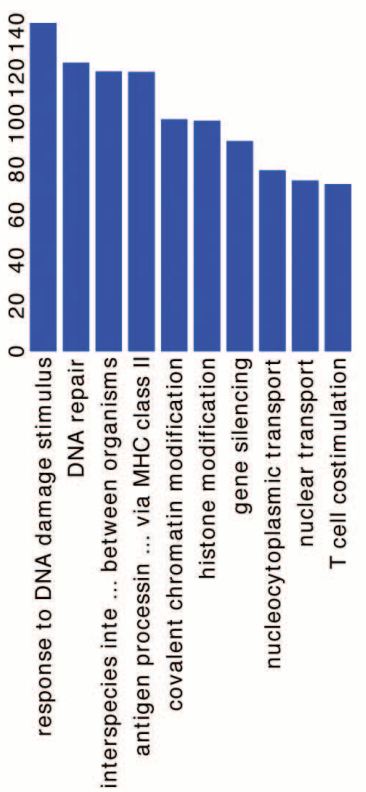

Disease Ontology

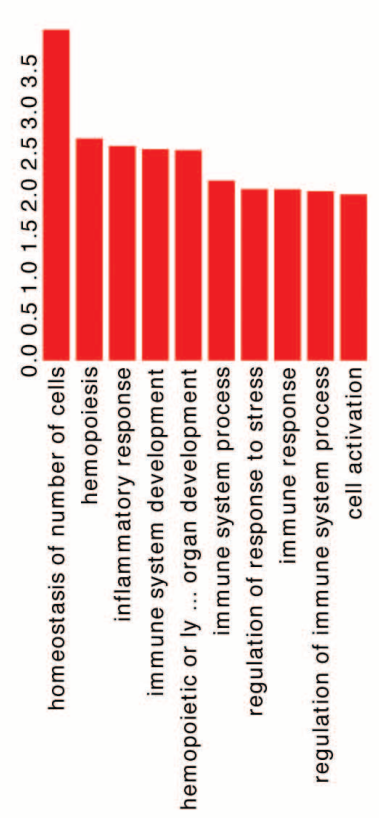

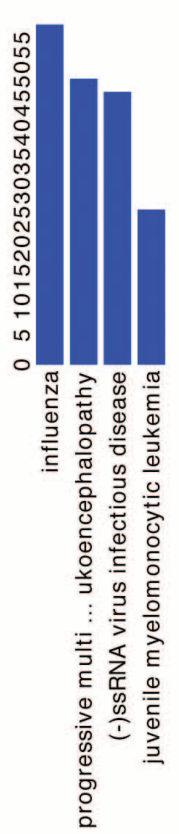

Lentiviral GT

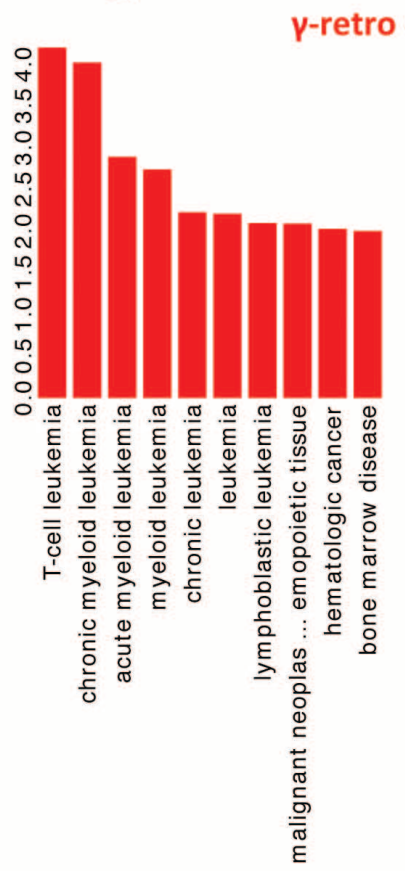

Fig. 5. Comparative analysis of vector integration sites in patients treated by gene therapy with lentiviral or $\gamma$-retroviral vectors. (A) Genomic distribution of ISs from five patients with WAS, treated by lentiviral ( $n=3$ subjects) or $\gamma$-retroviral ( $n=2$ subjects) vectors. Chromosome numbers are reported at the top of the graph. Refseq genes and IS frequency distributions are shown in bins of 1 million base pairs (Mbp) (gray, colored/red columns, respectively). (B) Chromatin modifications surrounding ISs. Probability density distributions of histone modifications mapped on $\mathrm{CD} 34^{+}$cells in a \pm 45 -kb window surrounding IS are shown as heat maps. The color intensity shows underrepresentation (blue) or over-representation (yellow) of each histone modification as compared with a random in silico-generated reference. Each row represents an in vitro or in vivo IS data set from the patients treated with lentiviral or $\gamma$-retroviral vectors. (C) Gene ontology of genes proximal to ISs. Biological process and diseases significantly associated with the functions of genes proximal to ISs in lentiviral and $\gamma$-retro gene therapy are represented as blue and red bars, respectively. The values on the $y$ axis show the fold enrichment scale for gene ontology categories. 
and S22). Thus, differently from retroviruses, $\mathrm{LV}$-w1.6W has a lower probability to interfere with the expression of genes involved in transformation of hematopoietic cells due to its wider genomic distribution.

We next assessed the presence of common insertion sites (CIS) to study potential insertional hotspots at the time of transduction and define surrogate markers of in vivo selection of clones. CIS were detected using a canonical statistical method that assumes a random distribution of vector integrations (49) and a novel analysis for CIS discovery based on a genome-wide Grubbs test for outliers (for details on both methods, see supplementary text). The highest-ranking-order WAS lentiviral CIS were KDM2A (targeted by 125 integrations), PACS1 (117) and TNRC6C (94) (table S23), which are well known hot spots in preclinical studies of lentiviral vectors $(50,51)$ and in the ALD lentiviral gene therapy trial (27) and have not been associated with clonal
Fig. 6. Common insertion sites and oncogenic hits in lentiviral versus $\gamma$-retroviral gene therapy. (A) Overlaps among CIS genes in lentiviral and $\gamma$-retroviral gene therapy. Genes proximal to CIS of order $>10$ are reported in the overlapping circles for lentiviral and $\gamma$-retro gene therapy (blue and red, respectively). Word clouds show the intensity of ISs clustering in each of the CIS genes (the bigger the gene name, the higher the number of ISs inside or in the proximity of that gene). The names of the $10 \mathrm{CIS}$ genes detected in both gene therapy trials are reported on the right at the intersection between the circles. (B) Incidence of ISs at two oncogenes in patients treated with lentiviral or $\gamma$-retroviral gene therapy. The comparative frequency distributions of insertions from lentiviral and $\gamma$-retroviral gene therapy in bins of $2 \mathrm{~kb}$ are shown for chromosomes 3 (left panel) and 11 (right panel). Mirror graph shows, for each bin, more frequent insertions in $\gamma$-retroviral gene therapy (columns above the $x$ axis) and more frequent insertions in lentiviral gene therapy (columns below the $x$ axis) ( ${ }^{*} P<$ 0.05 , Fisher exact test). Light gray columns at the top show transcriptional unit frequency for the same bins. Boxes at the bottom show a detail of MECOM and LMO2 loci, where ISs from the three lentiviral and two retroviral gene therapy patients are shown as sticks below the gene transcript. Raw IS data from the patients treated with the $\gamma$-retroviral vector were generated by Boztug et al. (12) and reprocessed through our informatic pipeline (table S3).

A
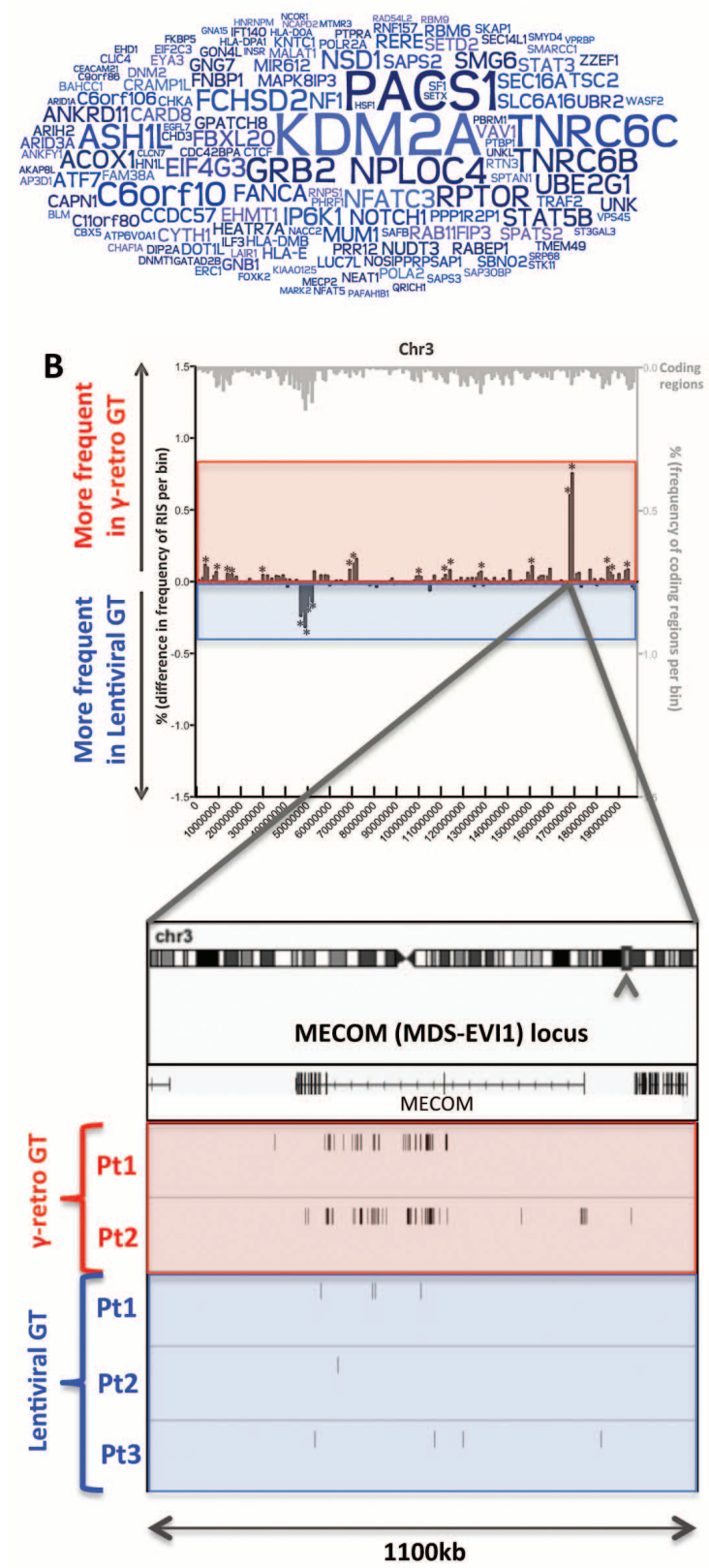

STAT5A
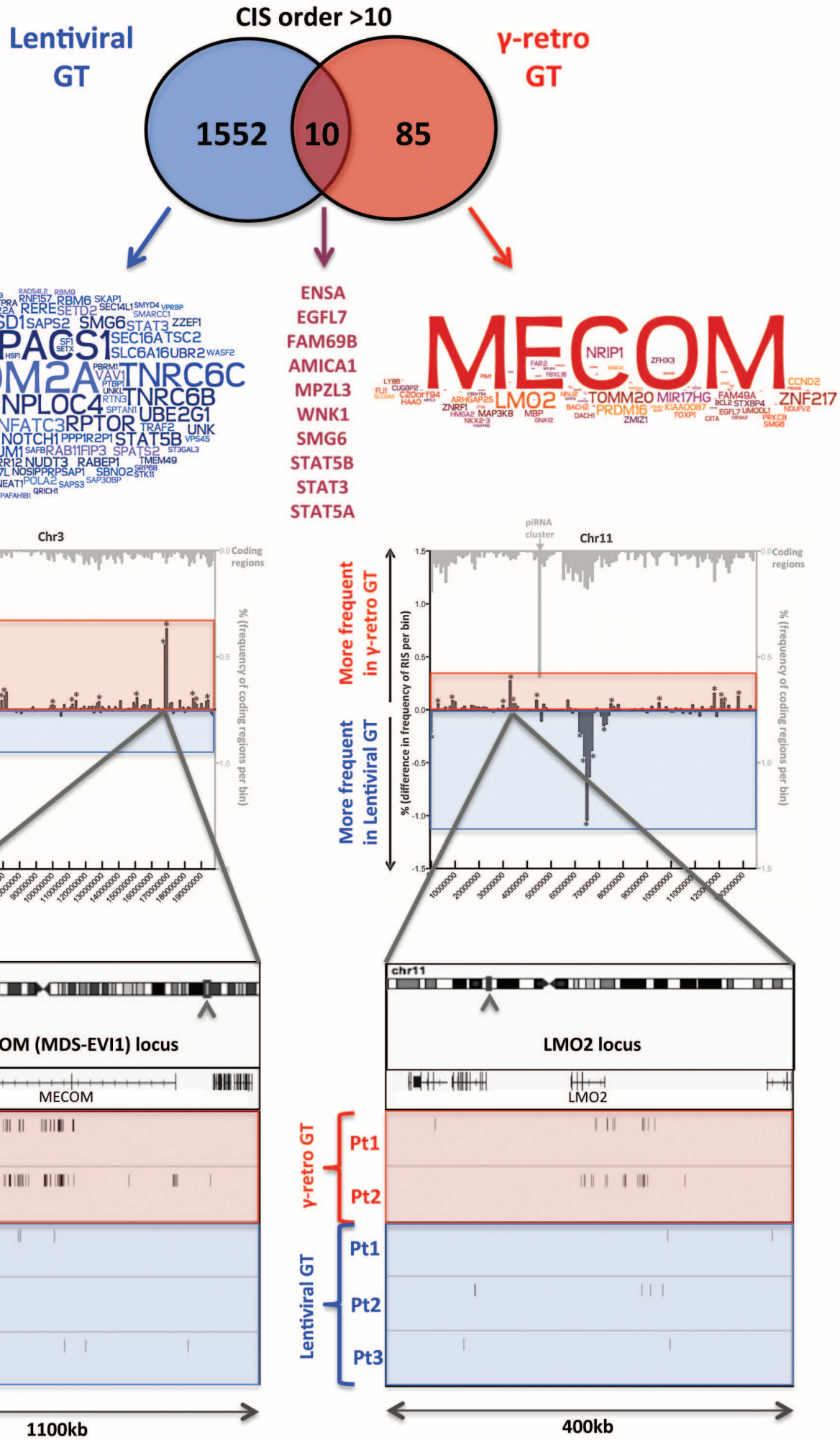
expansion (Fig. 6A and fig. S40). In contrast, $\gamma$-retroviral vector was found clustered in vivo in the MECOM (MDS-EVII) and LMO2 loci (Fig. $6 \mathrm{~A}$ ), hosting 67 and 15 of 11,294 integrations, respectively (12). In the current $\mathrm{LV}$-w1.6W gene therapy trial, these two genes were hit only by 10 and 5 out of 33,363 integrations, respectively (Fig. 6B). Additionally, the relative sequence reads associated to these ISs $(0.44 \%$ and $0.05 \%$ of reads from the same time point and sample source for $M E C O M$ and $L M O 2$, respectively) were below the average of all other insertions, and these specific integrants were not consistently detected over time. These observations were confirmed for insertions near other genes previously involved in clonal dominance, such as CCND2 and PRDM16 (fig. S15C). The HMGA2 locus was hit in both data sets (fig. S15C) but, in contrast to what was reported in the $\beta$-thalassemia patient (28), we did not observe over-representation of these integrations during follow-up. Together, these results indicate the lack of evident clonal expansions associated with CIS in proximity of known proto-oncogenes, suggesting that the insertional hot spots found in our trial are the product of vector integration biases at the time of transduction rather than in vivo genetic selection of ISs conferring a selective growth advantage.

\section{Discussion}

We have shown that infusion of autologous HSPC transduced with a lentiviral vector encoding a functional WASP gene resulted in robust and stable multilineage engraftment in three WAS patients who had been pretreated with a reduced intensity preparative regimen. The gene-corrected blood cells expressed WASP under control of a reconstituted WAS promoter. The patients showed improved immune function and amelioration of clinical manifestations of the disease, including protection from bleeding and severe infections, as well as resolution of eczema.

In this trial, the in vivo gene marking of hematopoiesis was superior ( $\sim 25$ to $50 \%$ of BM progenitors and mature PB myeloid cells) to that described in other lentiviral-based gene therapy trials for ALD and $\beta$-thalassemia $(27,28)$, which used myeloablative preparative regimens. The use of highly purified and homogenous batches of lentiviral vectors, optimized culture conditions and vector exposure (34), and the infusion of cells shortly after transduction likely accounts for the robust engraftment. In a parallel trial using the same procedures to treat patients with metachromatic leukodystrophy (MLD) (52), in vivo gene marking of HSPC was even higher (45 to $80 \%$ ). The preparative conditioning regimen in the latter trial was more intensive, suggesting that chemotherapy regimens can be modulated based on the engraftment threshold required for therapeutic benefit. Notably, stable engraftment of marked progenitor cells in vivo was higher in this lentiviral vector trial than in the previous WAS trial based on $\gamma$-retrovirus vector ( 3 to
$22 \%)(12)$. A selective advantage of lymphoid cells carrying a functional WAS gene (12) was observed in both clinical trials, in line with previous studies in the murine disease model $(12,30,33,53)$.

Although gene therapy did not normalize platelet counts in the patients, the counts did increase significantly and the platelets were of normal size, improvements that were sufficient to protect patients from bleeding and related disorders. Considering that the BM must contain a mixed population of WASP-positive and WASPnegative megakaryocytes and only platelets with normal levels of WASP were detected in peripheral blood, it is conceivable that a threshold level of WASP is required for platelets to exit the BM and/or to survive in the periphery. It is noteworthy that platelet counts in WAS patients treated by lentiviral gene therapy are in the range measured in patients with mixed donor/host chimerism after successful allogeneic BM transplant (7). A more intense conditioning regimen or the use of a lentiviral vector with a stronger promoter might result in a greater number of gene-corrected platelets. However, these options should be carefully balanced with the higher risk of toxicity, as reported for the conditioning used in allogeneic BM transplant, as well as of transactivation and insertional oncogenesis associated with strong enhancers and promoters, such as those of $\gamma$-retroviral vectors (54).

A consistent multilineage recapture of ISs 12 months after gene therapy indicated the active contribution of gene-corrected long-term HSPC to hematopoiesis. Our results lead us to propose that a takeover of hematopoietic output by longterm HSPC occurs at a defined time window after gene therapy, generating a diverse clonal repertoire in the blood progeny. The high proportion of ISs found in clonogenic BM progenitors that are shared with mature lineages validates IS-based tracking of stem cell dynamics and the colony assay as a representative surrogate readouts of in vivo HSPC activity. The calculated minimal number of 1700 to 6300 transduced active stem cells engrafted in vivo is consistent with data from the parallel MLD trial (52) and with estimates that repopulating HSPCs account for 1 out of $10^{4}$ to $10^{5}$ infused CD $34^{+}$cell populations (55), considering the impact of cell manipulation and the potentially limited BM homing after transplant.

The study of ISs from WAS patients treated with lentiviral or retroviral vector (12) allowed the first comparative study of the safety and clinical performance of two different vectors in the context of the same disease background. Our analyses expand previous observations that chromatin conformation and histone modifications differently affect the genomic distribution of retroviral vectors $(45,56)$, with the identification of $\mathrm{H} 3 \mathrm{~K} 4 \mathrm{me} 3$ and $\mathrm{H} 2 \mathrm{AZ}$ as two major chromatin determinants of differential insertions between lentiviruses and retroviruses. Differently from the retroviral gene therapy trial, where clonal enrichment of ISs tar- geting oncogenes like $M E C O M, C C N D 2$, and $L M O 2$ had already occurred at early follow-up, oncogenic ISs were not overrepresented in our patients, in agreement with previous preclinical and clinical studies $(27,34,51)$. Many genes and related categories targeted by lentivirus in our WAS patients were also hit in the parallel MLD trial (52) and in a previous ALD lentiviral trial (27), where no clonal dominance or leukemia have been reported up to 5 years after treatment (14). These findings are particularly relevant considering the high risk of lymphomagenesis described in WAS patients. The overall tendency of LV-w1.6W to distribute over megabase-wide areas and a broader spectrum of gene classes, together with the lower transformation potential of our SIN LTR-based construct, likely make lentiviral vector less prone to aberrantly interact with proto-oncogenes and induce genotoxicity. Collectively, although a definitive conclusion on safety must await the long-term observations, these data suggest that lentiviral-based HSPC gene therapy is safer than retroviral gene therapy.

\section{Materials and Methods}

\section{Clinical Protocol and Patients}

A phase I/II clinical trial of HSPC gene therapy for WAS was initiated in April 2010, after authorization by Istituto Superiore di Sanità on 15 March 2010 and by San Raffaele Scientific Institute Ethics Committee on 2 April 2010 (Eudract no. 2009-017346-32). The study promoter is HSR-TIGET, San Raffaele Hospital, Italy, and the financial sponsor of the study is Telethon Foundation. The medicinal product received Orphan Drug Designation (ODD) by the European Medicines Agency (EMA) (EU/3/12/998) and the FDA (ODD\#10-3043).

Male children with WAS suffering from a severe clinical condition (Zhu clinical score $\geq 3$ ) or severe mutation/absent WASP expression, without a suitable matched donor for allogeneic transplant or ineligible for HSPC transplantation (because of age $>5$ years or clinical features), were eligible for the study. The parents of all subjects provided written informed consent for experimental treatment. Details on the clinical study can be found at ClinicalTrials.gov (no. NCT01515462). Biological samples were obtained from WAS patients, healthy children or adults, with approval of the San Raffaele Scientific Institute's Ethics Committee and consent from parents or subjects.

\section{Lentiviral Vector}

The lentiviral vector used in this clinical trial is a third-generation SIN vector derived from HIV, named pCCLsin.cPPT.hw1.6.hWAS.WPREmut (abbreviated as LV-w1.6W), and it has been previously described $(3,34)$. This is a pseudotyped vector made by a core of HIV-1 structural proteins and enzymes, the envelope of the vesicular stomatitis virus (VSV), and a genome containing HIV-1 cis-acting sequences, no viral genes, and one expression cassette for the WAS transgene. 
In the cassette, the endogenous $1.6-\mathrm{kb}$ promoter of WAS controls the expression of WAS cDNA. The three vector components (core, envelope, and genome) are transiently expressed in vector producer cells by four different constructs: two core packaging constructs, the envelope construct, and the transfer vector construct. Only the vector construct is transferred and integrated into the target cells.

Clinical lots of vectors were produced under Good Manufacturing Practice (GMP) conditions by MolMed S.p.A. (Milan, Italy), a certified GMP facility. Vectors were produced by large-scale process based on transient quadritransfection in 293T cells, followed by purification through endonuclease treatment, anion exchange chromatography with gradient elution, gel filtration, resuspension in serum free media, $0.22 \mu \mathrm{m}$ filtration, and aseptic filling (fig. S1). Each lot was characterized in terms of titer, potency, purity, and safety aspects (tables $\mathrm{S} 1$ and $\mathrm{S} 2$ ).

\section{CD34 ${ }^{+}$Cell Gene Transfer}

Patients' CD $34^{+}$cell manipulation and transduction were performed at MolMed S.p.A. as detailed in fig. S2. Patients' BM was diluted, stratified with Lymphoprep (Axis Shield, Oslo, Norway), and centrifuged in order to collect mononuclear cells (MNC). $\mathrm{CD}^{+} 4^{+}$cell-positive selection from BM MNC was performed using immunomagnetic beads (CliniMACS, Miltenyi Biotec, Bergisch-Gladbach, Germany) and an immunomagnetic enrichment device. For MPB leukapheresis, CD $34^{+}$cells were processed using the CliniMACS device. Two independent lots of transduced cells were prepared for Pt1 (one for BM and one for MPB). The number of $\mathrm{CD} 34^{+}$cells collected from the $\mathrm{BM}$ and used for transduction ranged from 4.4 to $14.5 \times 10^{6} / \mathrm{kg}$ (table S3). MPB-derived CD34 ${ }^{+}$cells in Pt1 were $6.5 \times 10^{6} / \mathrm{kg}$ after thawing on day 3 (table S3). Purified CD $34^{+}$cells were seeded on VueLife bags (American Fluoroseal Corp., Gaithersburg, MD, USA) at $1 \times 10^{6}$ cells $/ \mathrm{ml}$ in serum-free CellGro SCGM Medium (Cell Genix Technologies, Freiburg, Germany) in the presence of cell culture grade stem cell factor (SCF) $300 \mathrm{ng} / \mathrm{ml}$ (Amgen Inc., Thousand Oaks, CA, USA), FLT3-L $300 \mathrm{ng} / \mathrm{ml}$, thrombopoietin (TPO) $100 \mathrm{ng} / \mathrm{ml}$, and IL-3 $60 \mathrm{ng} / \mathrm{ml}$ (all from Cell Genix Technologies). After 24 hours of prestimulation, cells were transduced with LVw1.6W at 100 multiplicity of infection (MOI) for two hits of transduction with a wash period of 12 to 14 hours between the vector exposures. Transduced cells were tested for immune phenotype, sterility, endotoxin, mycoplasma, large T antigen, E1A DNA, large T antigen DNA, clonogenic content, transduction efficiency, and replicationcompetent lentivirus (table S4). Cells were resuspended in saline and transferred in a syringe for infusion. An aliquot of cells was cultured in Iscove's modified Dulbecco's medium (IMDM), 10\% fetal bovine serum (Cambrex, East Rutherford, NJ, USA) with the same cytokines at $20 \mathrm{ng} / \mathrm{ml}$ concentration and harvested after 15 days to perform proviral integration evaluation by qPCR, WASP expression measurement, and integration profile analysis.

\section{Rationale for Conditioning Regimen}

Allogeneic HSPC transplant for WAS patients usually requires a high-dose myeloablative and immune suppressive regimen to deplete host bone marrow stem cells and prevent rejection or graftversus-host disease. Previous studies in the context of ADA-SCID gene therapy indicated that a reduced-dose chemotherapy regimen with busulfan at $25 \%$ of standard dose was sufficient to achieve substantial engraftment of gene-corrected cells while reducing conditioning-related toxicity $(9,15,16)$. Because WAS requires higher levels of stem cell correction with respect to SCID, our chemotherapy regimen is based on administration of both busulfan and fludarabine as depleting agents for endogenous HSPC. The dose of busulfan and fludarabine are $\sim 50 \%$ and $30 \%$ of the ones employed in standard allogeneic transplantation, respectively. Fludarabine was also used to break the homeostasis in the compartment of early lymphoid progenitors and to favor the establishment of a pool of corrected naïve T cells in the periphery, because the selective advantage for $\mathrm{WASP}^{+}$ cells is thought to take place mainly through peripheral expansion rather than during thymic differentiation $(57,58)$. mAb to CD20 was introduced as a depleting agent for B cells, and particularly of autoreactive cells, thereby facilitating the engraftment and expansion of gene-corrected B cells expressing WAS. In addition, antibody to CD20 was used as pre-emptive treatment for lymphoproliferative disorder due to Epstein-Barr virus (EBV), which represents a high risk factor for the development of lymphoma in WAS patients.

\section{Patients' Treatment}

In Pt1, mobilization of peripheral blood stem cells after granulocyte colony-stimulating factor (G-CSF) stimulation was performed to collect back-up HSPCs and store an adequate HSPC dose for subsequent transduction and reinfusion in case of need. In Pt2 and Pt3, due to their younger age, only a BM back-up was performed. A central venous catheter was implanted in all patients.

On day 3, autologous BM was collected from iliac crests under general anesthesia. A reducedintensity conditioning regimen was then administered before reinfusion of the autologous-engineered HSPC. It consisted of i.v. busulfan [bodyweightbased and area under the curve (AUC) adjusted-dose; range, 0.8 to $1.2 \mathrm{mg} / \mathrm{kg} /$ dose] administered consecutively in eight doses every 6 hours from days -3 to day -1 and i.v. fludarabine ( $30 \mathrm{mg} / \mathrm{sqm} /$ day) on days -3 and -2 . The actual doses and AUC of busulfan received by each patient are summarized in table S5. A single dose of $\mathrm{mAb}$ to $\mathrm{CD} 20$ (Rituximab, $375 \mathrm{mg} / \mathrm{sqm}$ ) was administered on day -22 . Transduced autologous LV-w1.6W $\mathrm{CD} 34^{+}$cells, manufactured as indicated above, were infused i.v. in $20 \mathrm{~min}$. Patients received antibacterial, antifungal, anti-Pneumocistis jirovecii, and antiviral prophylaxes according to local stan- dards. The treatment was administered at the Pediatric Immunology and BM Transplantation Unit, and patients were hospitalized in isolation for 40,70 , and 43 days, respectively.

\section{Patients' Features and Clinical Course After Gene Therapy.}

The clinical features before treatment and the current clinical conditions of the first three patients treated are summarized in Table 1. Pt1 was a 5.7-year-old boy lacking an human lymphocyte antigen-compatible donor, with clinical history of recurrent, frequent ENT and viral infections, skin petechiae, and moderate-severe eczema (Zhu score 3). His clinical course after treatment was uneventful. The second and third patients (Pt2 and Pt3) were younger and had a Zhu score of 4 , due to history of severe infections, severe eczema, and GI bleeding. Pt 2 was affected by a colitis associated with HHV-6 and CMV infection, as well as persistently elevated inflammatory indexes and vasculitis-like skin manifestations. Pt3 had important feeding problems, with severe GE reflux and food aversion, and was fed by nasogastric tube. Pt 2 developed an autoimmune thrombocytopenia, which is frequently observed after allogeneic transplant and was treated with IVIG and $\mathrm{mAb}$ to CD20. The patient experienced a Gram-negative sepsis complicated by a disseminated intravascular coagulation and acute respiratory distress syndrome (ARDS), for which he received steroids for about 5.5 months. Pt3's clinical course was characterized by respiratory infections related to aspiration due to the underlying GE reflux, including an episode of interstitial aspiration pneumonia, complicated by ARDS, and requiring steroid treatment for about 2 months. Both patients recovered well from these events without sequelae. No immune suppressive treatment was administered to the patients subsequently. Pt1 responded to vaccination with recombinant antigens, with production of specific antibodies and in vitro proliferative responses to tetanus toxoid.

\section{Laboratory Studies}

\section{CFC Assay}

CFC assay was performed, immediately after transduction or on ex vivo BM samples according to the manufacturer's procedure in Methocult medium (Stem Cell Technologies, Vancouver, Canada). At day 14, colonies were scored to determine number and type of colonies, singly picked and analyzed by qPCR to evaluate the percentage of transduction.

\section{Flow-Cytometric Analysis}

Surface staining of transduced $\mathrm{CD} 34^{+}$cells was performed with $\mathrm{mAb}$ to $\mathrm{CD} 34$ (8G12) and $\mathrm{mAb}$ to CD45 (HI30) (BD Biosciences, San Jose, CA). Cells from $\mathrm{PB}$ of patients and healthy donors, purified by standard density gradient technique (Lymphoprep), were stained for the expression of surface markers CD3 (SK7), CD4 (SK3), CD8 
(SK1), CD19 (SJ25C1), CD14 (MФP9), CD56 (NCAM16.2), CD25 (2A3), and CD41 (HIP8) (BD Biosciences) and of intracytoplasmatic expression of WASP. Detection of WASP was performed after permeabilization (Cytofix/Cytoperm kit, BD Biosciences) by two lots of rabbit polyclonal antibodies to human WASP (one of which was a gift of $\mathrm{H}$. Ochs) and followed by staining with a secondary Alexa 488 or 647 conjugated goat antibody to rabbit immunoglobulins (Ig) anti-rabbit antibodies. Tertiary rabbit antibodies to goat $\mathrm{Ig}$ (conjugated to Alexa 488 or 647) (all from Invitrogen, Carlsbad, CA, USA) were used. For analyses of TCR repertoire, 24 different TCR V $\beta$ specificities were analyzed by flow cytometric analysis by I0Test Beta Mark kit (Immunotech, Marseilles, France) according to the manufacturer's procedure. Cells were acquired using a FACSCantoII (BD Biosciences) and analyzed with Flow Jo Software (Tree Star Inc., Ashland, OR, USA).

\section{Western Blot Analysis}

Western blot was performed as previously described $(3,34)$, using antibody to human WASP (H250; Santa Cruz Biotechnologies, Santa Cruz, California, USA) and antibody to human glyceraldehyde-3phosphate dehydrogenase (Chemicon, Temecula, California, USA), followed by secondary horseradish peroxidase-coupled antibodies (DAKO A/S, Glostrup, Denmark).

\section{Purification of Peripheral Blood and Bone Marrow Lineages}

CD3, CD4, CD8, CD14, CD15, CD19, and CD56 cells were purified from MNC from $\mathrm{PB}$. CD3, CD15, CD19, CD34, CD56, CD61, and glycophorin were purified from BM-derived MNCs by positive selection with immunomagnetic beads according to the manufacturer's procedure (Miltenyi Biotec, Bergisch-Gladbach, Germany).

\section{Determination of Vector Copy Number by Real-Time PCR}

To evaluate the number of lentiviral vector copies integrated per genome, a qPCR was performed using specific primer and probes for human telomerase and lentiviral vector, as described previously (34). A reference standard was obtained from serially diluted transduced human $\mathrm{T}$ cell lines carrying one copy of integrated lentiviral vector. Results of integrated vector copies were normalized for the number of evaluated genomes. As a negative control, samples of untransduced cells were used. All the reactions were performed according to the manufacturer's instructions and analyzed with an ABI PRISM 7900 sequence detection system (Applied Biosystem, Foster City, CA).

\section{Vector Integration Analyses and Bioinformatics}

These methods are described extensively in the Supplementary Materials.

\section{In vitro Suppression Assays}

Suppression assays were performed as previously described (59). Briefly, $\mathrm{CD} 4^{+} \mathrm{CD} 25^{\text {high }} \mathrm{CD} 127^{- \text {low }} \mathrm{T}_{\text {reg }}$ cells and $\mathrm{CD}^{+} \mathrm{CD} 25^{-}$effector T cells were isolated from MNC by fluorescence-activated cell sorting. Cells from healthy subjects were used as control. A total of $15 \times 10^{3} \mathrm{CD} 4^{+} \mathrm{CD} 25^{-}$effector T cells were stimulated by CD3-depleted antigenpresenting cells and $1 \mu \mathrm{g} / \mathrm{ml}$ of soluble mAbs to CD3 (Orthoclone OKT3, Janssen-Cilag). Suppressive activity of $\mathrm{nT}_{\text {reg }}$ cells was assessed by coculture of effector T cells with $\mathrm{nT}_{\text {reg }}$ cells at a 1:1 ratio. Proliferation was evaluated by 16 hours liquid scintillation counting of $3 \mathrm{H}$-thymidine (Amersham Biosciences) incorporation after 96 hours of stimulation.

\section{Analysis of the NK Cell Immunological Synapse}

NK cell immunological synapses were analyzed as previously described (60). In brief, NK cells were cocultured with K562 target cells for $30 \mathrm{~min}$ to permit the formation of conjugates. F-actin and WASP accumulation, as well as perforin and MTOC polarization were measured to determine synapse maturity. The distance of the MTOC from the synapse was measured using the Velocity software package (Improvision-Perkin Elmer, Lexington, MA). Mean distances of the MTOC to the immunological synapse are a measure of synapse maturity and were compared by using the MannWhitney rank sum test.

\section{Chromium-Release Cytotoxicity Assay}

The ability of NK cells to lyse major histocompatibility complex devoid target cells was performed using a standard chromium-release cytotoxicity assay (61). Briefly, K562 target cells were labeled with $60 \mu \mathrm{Ci}$ of $\mathrm{Na}_{2}\left({ }^{51} \mathrm{CrO}_{4}\right.$ ) (Perkin Elmer Inc., Waltham, MA, USA) per $10^{6}$ cells for 2 hours at $37^{\circ} \mathrm{C}$ and resuspended at used concentration. Effectors $\mathrm{MNC}$ were isolated and coincubated at serial diluted effectors to target (E:T) ratios of 60:1, 30:1, 15:1, 7.5:1, and 3.75:1 in duplicates in a 96-well v-bottom plate (Corning Costar, NY, USA) for 4 hours at $37^{\circ} \mathrm{C}$ in the atmosphere of $5 \% \mathrm{CO}_{2}$. Radioactivity was measured in the culture supernatants by Canberra Packard Cobra II Auto Gamma Counter (Canberra Packard, Canberra, Canada). Percentage of specific target cell lysis was calculated as follows: (experimental.cpmspontaneous.cpm)/(maximal.cpm-spontaneous. $\mathrm{cpm}) \times 100$. For spontaneous release, targets were cultured with medium alone, and for maximum release in 3\% (v/v) Triton X-100 (Sigma, St. Louis, $\mathrm{MO})$ in phosphate-buffered saline.

\section{$T$ Cell Response to Antibody to CD3}

$\mathrm{T}$ cell response to antibody to $\mathrm{CD} 3$ was performed as previously described (62). Briefly, $0.1 \times 10^{6} \mathrm{~PB} \mathrm{MNC}$ were seeded into a roundbottom 96-well plate in IMDM medium containing $5 \%$ human $\mathrm{AB}$ serum (Lonza, Basel, Switzerland) in the presence of coated 1 or $10 \mu \mathrm{g} / \mathrm{ml}$ of antibody to CD3 (Orthoclone OKT3, Janssen-Cilag). Proliferation was assessed by $3 \mathrm{H}$-thymidine (Amersham Biosciences) incorporation after 72 or 96 hours of stimulation. Data were expressed as the maximal counts per minute (cpm) and stimulation index (SI, calculated as cpm/background cpm). For proliferation assay on untransformed $\mathrm{T}$ cell lines, overnight starved T cells were stained with $2 \mu \mathrm{M}$ carboxyfluorescein diacetate succinimidyl ester (CFSE), and $0.1 \times 10^{6}$ cells were cultured in a round-bottom 96-well plate coated with different concentration (from 0.01 to $10 \mu \mathrm{g} / \mathrm{ml}$ ) of antibody to CD3. Proliferation was assessed after 72 hours evaluating CFSE dilution on a FACSCantoII, and data were analyzed with Flow Jo Software.

\section{References and Notes}

1. L. D. Notarangelo, C. H. Miao, H. D. Ochs, Wiskott-Aldrich syndrome. Curr. Opin. Hematol. 15, 30-36 (2008). doi: 10.1097/MOH.0b013e3282f30448; pmid: 18043243

2. M. Catucci, M. C. Castiello, F. Pala, M. Bosticardo, A. Villa, Autoimmunity in Wiskott-Aldrich syndrome: An unsolved enigma. Front. Immunol. 3, 209 (2012). doi: 10.3389/fimmu.2012.00209; pmid: 22826711

3. L. Dupré et al., Lentiviral vector-mediated gene transfer in T cells from Wiskott-Aldrich syndrome patients leads to functional correction. Mol. Ther. 10, 903-915 (2004). doi: 10.1016/j.ymthe.2004.08.008; pmid: 15509508

4. M. Bosticardo, F. Marangoni, A. Aiuti, A. Villa, M. Grazia Roncarolo, Recent advances in understanding the pathophysiology of Wiskott-Aldrich syndrome. Blood 113, 6288-6295 (2009). doi: 10.1182/blood-2008-12115253; pmid: 19351959

5. H. D. Ochs, A. H. Filipovich, P. Veys, M. J. Cowan, N. Kapoor, Wiskott-Aldrich syndrome: Diagnosis, clinical and laboratory manifestations, and treatment. Biol. Blood Marrow Transplant. 15 (suppl.), 84-90 (2009). doi: 10.1016/j.bbmt.2008.10.007; pmid: 19147084

6. H. Ozsahin et al., Long-term outcome following hematopoietic stem-cell transplantation in Wiskott-Aldrich syndrome: Collaborative study of the European Society for Immunodeficiencies and European Group for Blood and Marrow Transplantation. Blood 111, 439-445 (2008). doi: 10.1182/blood-2007-03-076679; pmid: 17901250

7. D. Moratto et al., Long-term outcome and lineage-specific chimerism in 194 patients with Wiskott-Aldrich syndrome treated by hematopoietic cell transplantation in the period 1980-2009: An international collaborative study. Blood 118, 1675-1684 (2011). doi: 10.1182/blood-2010-11-319376; pmid: 21659547

8. C. R. Shin et al., Outcomes following hematopoietic cell transplantation for Wiskott-Aldrich syndrome. Bone Marrow Transplant. 47, 1428-1435 (2012). doi: 10.1038/bmt.2012.31; pmid: 22426750

9. A. Aiuti et al., Gene therapy for immunodeficiency due to adenosine deaminase deficiency. N. Engl. J. Med. 360, 447-458 (2009). doi: 10.1056/NEJMoa0805817 pmid: 19179314

10. S. Hacein-Bey-Abina et al., Efficacy of gene therapy for X-linked severe combined immunodeficiency. N. Engl. J. Med. 363, 355-364 (2010). doi: 10.1056/ NEJMoa1000164; pmid: 20660403

11. H. B. Gaspar et al., Long-term persistence of a polyclonal $\mathrm{T}$ cell repertoire after gene therapy for $\mathrm{X}$-linked severe combined immunodeficiency. Sci. Transl. Med. 3, 97ra79 (2011). doi: 10.1126/scitranslmed.3002715; pmid: 21865537

12. K. Boztug et al., Stem-cell gene therapy for the Wiskott-Aldrich syndrome. N. Engl. J. Med. 363, 1918-1927 (2010). doi: 10.1056/NEJMoa1003548; pmid: 21067383

13. H. B. Gaspar et al., How I treat ADA deficiency. Blood 114, 3524-3532 (2009). doi: 10.1182/blood-2009-06189209; pmid: 19638621

14. L. W. Seymour, A. J. Thrasher, Gene therapy matures in the clinic. Nat. Biotechnol. 30, 588-593 (2012). doi: 10.1038/nbt.2290; pmid: 22781675

15. F. Candotti et al., Gene therapy for adenosine deaminase-deficient severe combined immune deficiency: Clinical comparison of retroviral vectors and 
treatment plans. Blood 120, 3635-3646 (2012). doi: 10.1182/blood-2012-02-400937; pmid: 22968453

16. A. Aiuti et al., Correction of ADA-SCID by stem cell gene therapy combined with nonmyeloablative conditioning. Science 296, 2410-2413 (2002). doi: 10.1126/ science.1070104; pmid: 12089448

17. S. J. Howe et al., Insertional mutagenesis combined with acquired somatic mutations causes leukemogenesis following gene therapy of SCID-X1 patients. J. Clin. Invest. 118, 3143-3150 (2008). doi: 10.1172/]Cl35798; pmid: 18688286

18. S. Hacein-Bey-Abina et al., Insertional oncogenesis in 4 patients after retrovirus-mediated gene therapy of SCID-X1. J. Clin. Invest. 118, 3132-3142 (2008). doi: 10.1172/]Cl35700; pmid: 18688285

19. S. Stein et al., Genomic instability and myelodysplasia with monosomy 7 consequent to EVI1 activation after gene therapy for chronic granulomatous disease. Nat. Med. 16 198-204 (2010). doi: 10.1038/nm.2088; pmid: 20098431

20. M. Cavazzana-Calvo, A. Fischer, S. Hacein-Bey-Abina, A. Aiuti, Gene therapy for primary immunodeficiencies: Part 1. Curr. Opin. Immunol. 24, 580-584 (2012). doi: 10.1016/j.coi.2012.08.008; pmid: 22981681

21. G. P. Wang et al., Dynamics of gene-modified progenitor cells analyzed by tracking retroviral integration sites in a human SCID-X1 gene therapy trial. Blood $\mathbf{1 1 5}$ 4356-4366 (2010). doi: 10.1182/blood-2009-12257352; pmid: 20228274

22. A. Deichmann et al., Insertion sites in engrafted cells cluster within a limited repertoire of genomic areas after gammaretroviral vector gene therapy. Mol. Ther. 19, 2031-2039 (2011). doi: 10.1038/mt.2011.178; pmid: 21862999

23. L. Biasco, C. Baricordi, A. Aiuti, Retroviral integrations in gene therapy trials. Mol. Ther. 20, 709-716 (2012). doi: 10.1038/mt.2011.289; pmid: 22252453

24. J. Corrigan-Curay et al., Challenges in vector and tria design using retroviral vectors for long-term gene correction in hematopoietic stem cell gene therapy. Mol. Ther. 20, 1084-1094 (2012). doi: 10.1038/mt.2012.93 pmid: 22652996

25. L. Naldini, Ex vivo gene transfer and correction for cell-based therapies. Nat. Rev. Genet. 12, 301-315 (2011). doi: 10.1038/nrg2985; pmid: 21445084

26. E. Montini et al., Hematopoietic stem cell gene transfer in a tumor-prone mouse model uncovers low genotoxicity of lentiviral vector integration. Nat. Biotechnol. 24, 687-696 (2006). doi: 10.1038/nbt1216; pmid: 16732270

27. N. Cartier et al., Hematopoietic stem cell gene therapy with a lentiviral vector in X-linked adrenoleukodystrophy. Science 326, 818-823 (2009). doi: 10.1126/ science.1171242; pmid: 19892975

28. M. Cavazzana-Calvo et al., Transfusion independence and HMGA2 activation after gene therapy of human $\beta$-thalassaemia. Nature 467, 318-322 (2010). doi: 10.1038/nature09328; pmid: 20844535

29. C. Bartholomae, Assessing the integration profile of lentiviral vectors in gene therapy for X-adrenoleukodystrophy. Hum. Gene Ther. 23, A3 (2012) (abstract).

30. L. Dupré et al., Efficacy of gene therapy for Wiskott-Aldrich syndrome using a WAS promoter/cDNA-containing lentiviral vector and nonlethal irradiation. Hum. Gene Ther 17, 303-313 (2006). doi: 10.1089/hum.2006.17.303; pmid: 16544979

31. S. Charrier et al., Lentiviral vectors targeting WASp expression to hematopoietic cells, efficiently transduce and correct cells from WAS patients. Gene Ther. 14, 415-428 (2007). doi: 10.1038/sj.gt.3302863; pmid: 17051251

32. F. Marangoni et al., WASP regulates suppressor activity of human and murine CD4(+)CD25(+)FOXP3(+) natural regulatory T cells. J. Exp. Med. 204, 369-380 (2007). doi: 10.1084/jem.20061334; pmid: 17296785

33. M. Bosticardo et al., Lentiviral-mediated gene therapy leads to improvement of B-cell functionality in a murine model of Wiskott-Aldrich syndrome. J. Allergy Clin. Immunol. 127, 1376, e5 (2011). doi: 10.1016/j. jaci.2011.03.030; pmid: 21531013

34. S. Scaramuzza et al., Preclinical safety and efficacy of human CD34(+) cells transduced with lentiviral vector fo the treatment of Wiskott-Aldrich syndrome. Mol. Ther. 21, 175-184 (2013).pmid: 22371846
35. E. Montini et al., The genotoxic potential of retroviral vectors is strongly modulated by vector design and integration site selection in a mouse model of HSC gene therapy. J. Clin. Invest. 119, 964-975 (2009). doi: 10.1172/]Cl37630; pmid: 19307726

36. U. Modlich et al., Insertional transformation of hematopoietic cells by self-inactivating lentiviral and gammaretroviral vectors. Mol. Ther. 17, 1919-1928 (2009). doi: 10.1038/mt.2009.179; pmid: 19672245

37. F. Marangoni et al., Evidence for long-term efficacy and safety of gene therapy for Wiskott-Aldrich syndrome in preclinical models. Mol. Ther. 17, 1073-1082 (2009). doi: 10.1038/mt.2009.31; pmid: 19259069

38. A. Aiuti, R. Bacchetta, R. Seger, A. Villa, M. Cavazzana-Calvo, Gene therapy for primary immunodeficiencies: Part 2. Curr. Opin. Immunol. 24, 585-591 (2012). doi: 10.1016/j. coi.2012.07.012; pmid: 22909900

39. Q. Zhu et al., Wiskott-Aldrich syndrome/X-linked thrombocytopenia: WASP gene mutations, protein expression, and phenotype. Blood 90, 2680-2689 (1997). pmid: 9326235

40. M. H. Maillard et al., The Wiskott-Aldrich syndrome protein is required for the function of $\mathrm{CD}^{+} \mathrm{CD} 25^{+} \mathrm{Foxp} 3^{+}$ regulatory T cells. J. Exp. Med. 204, 381-391 (2007). doi: 10.1084/jem.20061338; pmid: 17296786

41. ]. S. Orange et al., Wiskott-Aldrich syndrome protein is required for NK cell cytotoxicity and colocalizes with actin to NK cell-activating immunologic synapses. Proc. Natl. Acad. Sci. U.S.A. 99, 11351-11356 (2002) doi: 10.1073/pnas.162376099; pmid: 12177428

42. M. Schmidt et al., High-resolution insertion-site analysis by linear amplification-mediated PCR (LAM-PCR). Nat. Methods 4, 1051-1057 (2007). doi: 10.1038/ nmeth1103; pmid: 18049469

43. A. Paruzynski et al., Genome-wide high-throughput integrome analyses by nrLAM-PCR and next-generation sequencing. Nat. Protoc. 5, 1379-1395 (2010) doi: 10.1038/nprot.2010.87; pmid: 20671722

44. A. Chao, An overview of closed capture-recapture models. J. Agric. Biol. Environ. Stat. 6, 158-175 (2001) doi: $10.1198 / 108571101750524670$

45. L. Biasco et al., Integration profile of retroviral vector in gene therapy treated patients is cell-specific according to gene expression and chromatin conformation of target cell. EMBO Mol. Med. 3 89-101 (2011). doi: 10.1002/emmm.201000108; pmid: 21243617

46. G. P. Wang, A. Ciuffi, ]. Leipzig, C. C. Berry, F. D. Bushman, HIV integration site selection: Analysis by massively parallel pyrosequencing reveals association with epigenetic modifications. Genome Res. 17, 1186-1194 (2007). doi: 10.1101/gr.6286907; pmid: 17545577

47. K. Cui et al., Chromatin signatures in multipotent human hematopoietic stem cells indicate the fate of bivalent genes during differentiation. Cell Stem Cell 4, 80-93 (2009). doi: 10.1016/j.stem.2008.11.011; pmid: 19128795

48. C. Y. McLean et al., GREAT improves functional interpretation of cis-regulatory regions. Nat. Biotechnol. 28, 495-501 (2010). doi: 10.1038/nbt.1630; pmid: 20436461

49. U. Abel et al., Analyzing the number of common integration sites of viral vectors: New methods and computer programs. PLoS ONE 6, e24247 (2011). doi: 10.1371/journal.pone.0024247; pmid: 22022353

50. A. Biffi et al., Lentiviral vector common integration sites in preclinical models and a clinical trial reflect a benign integration bias and not oncogenic selection. Blood 117, 5332-5339 (2011). doi: 10.1182/blood-2010-09-306761; pmid: 21403130

51. C. Cattoglio et al., Hot spots of retroviral integration in human CD34+ hematopoietic cells. Blood 110, 1770-1778 (2007). doi: 10.1182/blood-2007-01-068759; pmid: 17507662

52. A. Biffi et al., Lentiviral hematopoietic stem cell gene therapy benefits metachromatic leukodystrophy. Science 341, 1233158 (2013); .doi: 10.1126/science. 1233158

53. L. S. Westerberg et al., Wiskott-Aldrich syndrome protein (WASP) and N-WASP are critical for peripheral B-cell development and function. Blood 119, 3966-3974 (2012). doi: 10.1182/blood-2010-09-308197; pmid: 22411869

54. A. Astrakhan et al., Ubiquitous high-level gene expression in hematopoietic lineages provides effective lentiviral gene therapy of murine Wiskott-Aldrich syndrome. Blood 119, 4395-4407 (2012). doi: 10.1182 blood-2011-03-340711; pmid: 22431569

55. L. V. Bystrykh, E. Verovskaya, E. Zwart, M. Broekhuis, G. de Haan, Counting stem cells: Methodological constraints. Nat. Methods 9, 567-574 (2012). doi: 10.1038/nmeth.2043; pmid: 22669654

56. C. Cattoglio et al., High-definition mapping of retroviral integration sites identifies active regulatory elements in human multipotent hematopoietic progenitors. Blood 116, 5507-5517 (2010). doi: 10.1182/blood-2010-05283523; pmid: 20864581

57. K. Yamaguchi et al., Mixed chimera status of 12 patients with Wiskott-Aldrich syndrome (WAS) after hematopoietic stem cell transplantation: Evaluation by flow cytometric analysis of intracellular WAS protein expression. Blood 100, 1208-1214 (2002). doi: 10.1182/blood-2002-010211; pmid: 12149199

58. T. Wada et al., Second-site mutation in the WiskottAldrich syndrome (WAS) protein gene causes somatic mosaicism in two WAS siblings. J. Clin. Invest. 111, 1389-1397 (2003). pmid: 12727931

59. A. V. Sauer et al., Alterations in the adenosine metabolism and CD39/CD73 adenosinergic machinery cause loss of Treg cell function and autoimmunity in ADA-deficient SCID. Blood 119 , 1428-1439 (2012). doi: 10.1182/blood-2011-07366781; pmid: 22184407

60. J. S. Orange et al., IL-2 induces a WAVE2-dependent pathway for actin reorganization that enables WASpindependent human NK cell function. ]. Clin. Invest. 121 1535-1548 (2011). doi: 10.1172/]CI44862; pmid: 21383498

61. D. S. Heo et al., Evaluation of tetrazolium-based semiautomatic colorimetric assay for measurement of human antitumor cytotoxicity. Cancer Res. 50, 3681-3690 (1990). pmid: 2340518

62. S. Trifari et al., Defective Th1 cytokine gene transcription in CD4+ and CD8+ T cells from Wiskott-Aldrich syndrome patients. J. Immunol. 177, 7451-7461 (2006). pmid: 17082665

Acknowledgments: This work was supported by Fondazione Telethon (TIGET core grant to A.A., M.G.R., L.N., E.M., and A.V.); the European Commission (CLINIGENE LSHB-CT2006-018933 to M.G.R. and A.A.; CELL-PID HEALTH-F5-2010-261387 to A.A.; GA 222878 PERSIST and ERC, Advanced Grant 249845 Targeting Gene Therapy to L.N.) and Ministero della Salute (Ricerca Finalizzata, 005/RF-2009-1485896 to A.A. and A.V.; and Progetto Giovani Ricercatori GR-2007-684057 to E.M.). We thank all medical staff of the HSR-TIGET Pediatric Clinical Research Unit, Pediatric Immunohematology, and Bone Marrow Transplant Unit; R. Fiori, P. Silvani, E. Zoia, A. Mandelli, and A. Moscatelli for patient care; L. Dupre for initiating the project and conducting preclinical studies; R. Chiesa and B. Cappelli for initial contributions to the clinical trial; M. Gabaldo for support with project management; M. Bonopane and G. Tomaselli for clinical trial management; P. Massariello and other MolMed staff for patient cell manipulation; H. Ochs and L. Notarangelo for the antibody to WASP; G. Royal, L. King, and F. Govani for technical help on 454-pyrosequencing and sequence data management; ]. Appleby and A. Chuang for advice and support; and F. Pasinelli for continuous support to this project. We are indebted to the patients and their families for their commitment and endurance. L.N. is an inventor of several patents on lentiviral vector technology that are owned by the Salk Institute and Cell Genesis and are licensed to Lentigen. L.N. is entitled to receive royalties from one of these patents (U.S. Patent no. 6,013,516 with Salk Institute).

\section{Supplementary Materials}

www.sciencemag.org/cgi/content/full/science.1233151/DC

Supplementary Text

Figs. S1 to $\mathrm{S} 46$

Tables S1 to S25

References

26 November 2012; accepted 24 June 2013

Published online 11 July 2013;

10.1126/science.1233151 


\section{Lentiviral Hematopoietic Stem Cell Gene Therapy in Patients with Wiskott-Aldrich Syndrome}

Alessandro Aiuti et al.

Science 341, (2013);

DOI: $10.1126 /$ science. 1233151

This copy is for your personal, non-commercial use only.

If you wish to distribute this article to others, you can order high-quality copies for your colleagues, clients, or customers by clicking here.

Permission to republish or repurpose articles or portions of articles can be obtained by following the guidelines here.

The following resources related to this article are available online at www.sciencemag.org (this information is current as of December 8, 2014 ):

Updated information and services, including high-resolution figures, can be found in the online version of this article at:

http://www.sciencemag.org/content/341/6148/1233151.full.html

Supporting Online Material can be found at:

http://www.sciencemag.org/content/suppl/2013/07/11/science.1233151.DC1.html

A list of selected additional articles on the Science Web sites related to this article can be found at:

http://www.sciencemag.org/content/341/6148/1233151.full.html\#related

This article cites 62 articles, 25 of which can be accessed free:

http://www.sciencemag.org/content/341/6148/1233151.full.html\#ref-list-1

This article has been cited by 20 articles hosted by HighWire Press; see:

http://www.sciencemag.org/content/341/6148/1233151.full.html\#related-urls

This article appears in the following subject collections:

Medicine, Diseases

http://www.sciencemag.org/cgi/collection/medicine 